\author{
UNIVERSIDADE DE SÃO PAULO \\ FACULDADE DE ODONTOLOGIA DE RIBEIRÃO PRETO
}

ELAINE MACHADO PINGUEIRO OKADA

EFEITO dO LASER DE BAIXA POTÊNCIA APÓS A EXPANSÃo RÁPIDA dA MAXILA, NA ATIVAÇÃo dE REGIÕES CEREBRAIS RELACIONADAS À NOCICEPÇÃO 


\section{EFEITO dO LASER DE BAIXA POTÊNCIA APÓS A EXPANSÃo RÁPIDA DA MAXILA, NA ATIVAÇÃO DE REGIÕES CEREBRAIS RELACIONADAS À NOCICEPÇÃO}

Dissertação apresentada à Faculdade de
Odontologia de Ribeirão Preto da
Universidade de São Paulo, para a
obtenção do Título de Mestre em
Ciências.

Programa: Odontopediatria

Área de Concentração: Odontopediatria

Orientadora: Profa. Dra. Maria Bernadete

Sasso Stuani

Ribeirão Preto 
AUTORIZO A REPRODUÇÃO E DIVULGAÇÃO TOTAL OU PARCIAL DESTE TRABALHO, POR QUALQUER MEIO CONVENCIONAL OU ELETRÔNICO, PARA FINS DE ESTUDO E PESQUISA, DESDE QUE CITADA A FONTE.

Pingueiro-Okada, Elaine Machado

Efeito do laser de baixa potência após a expansão rápida da maxila, na ativação de regiões cerebrais relacionadas à nocicepção. Elaine Machado Pingueiro-Okada, Ribeirão Preto, 2012.

65 p.; II.; $30 \mathrm{~cm}$

Dissertação de Mestrado apresentada à Faculdade de Odontologia de Ribeirão Preto/USP - Área de concentração: Odontopediatria.

Orientadora: Stuani, Maria Bernadete Sasso

1. Ortodontia, 2. Terapia a Laser de Baixa Intensidade, 3. Nocicepção, 4. Proteína c-fos 
PINGUEIRO-OKADA, Elaine Machado

Efeito do laser de baixa potência após a expansão rápida da maxila, na ativação de regiões cerebrais relacionadas à nocicepção.

Dissertação apresentada à Faculdade de Odontologia de Ribeirão Preto da Universidade de São Paulo, para a obtenção do Título de Mestre em Ciências.

Área de Concentração: Odontopediatria

Aprovado em:

\section{Banca Examinadora}

Prof. Dr.

Instituição:

Julgamento:

Assinatura:

Prof. Dr.

Instituição:

Julgamento:

Assinatura:

Prof. Dr.

Instituição:

Julgamento:

Assinatura: 


\section{DADOS CURRICULARES}

\section{ELAINE MACHADO PINGUEIRO OKADA}

Nascimento:

28 de outubro de 1985- Ribeirão Preto- SP

Filiação:

Ester Vieira Machado Pingueiro

Arlindo Pingueiro

2004-2008

Curso de Graduação

Faculdade de Odontologia de Araraquara da Universidade Estadual de São Paulo - FOAr/UNESP.

$2009-2012$

Curso de Pós-Graduação em Odontopediatria, nível de Mestrado na Faculdade de Odontologia de Ribeirão Preto da Universidade de São Paulo - FORP/USP. 


\section{DEDICATÓRIA}

A Deus, pelo dom da vida! pelo seu grande e infinito amor para comigo! Não tenho palavras pra agradecer por sua bondade! A Deus seja dada toda honra e glória!

Elevo os meus olhos para os montes, de onde vem o meu socorro.

O meu socorro vem do SENHOR que fez o céu e a terra.

Não deixará vacilar o teu pé; aquele que te guarda não tosquenejará.

Eis que não tosquenejará nem dormirá o guarda de Israel.

O SENHOR é quem te guarda; o SENHOR é a tua sombra à tua direita.

O sol não te molestará de dia nem a lua de noite.

O SENHOR te guardará de todo o mal; guardará a tua alma.

O SENHOR guardará a tua entrada e a tua saída, desde agora e para sempre.

Salmos 121:1-8.

Aos meus pais, Arlindo Pingueiro e Ester Vieira Machado Pingueiro. Vocês são meu alicerce, meu exemplo! Meu pai, homem esforçado, amoroso, sério, sempre me estimulou e ajudou em cada passo. Minha mãe, mulher virtuosa, muito amorosa, que sempre tem bons conselhos. A senhora me mostrou que sempre há mais pra aprender e abriu meus olhos pra este belo mundo do conhecimento! Obrigada por sempre estarem ao meu lado, lutando comigo por meus sonhos, me apoiando em tudo! Amo muito vocês!

A minha querida irmã Raquel Angélica Machado Pingueiro. Como é bom saber que sempre posso contar contigo! Sua amizade é preciosa pra mim! Obrigada por me ajudar! Te amo muito pequenina!

Ao meu marido Adriano Kenji Okada. Meu príncipe, eterno namorado, amigo, companheiro, você é um presente precioso de Deus em minha vida! Você vibrou comigo em cada vitória e me ajudou a superar cada obstáculo! Obrigada por compreender momentos de minha ausência e reclusão pra concluir esta dissertação. Amo muito você! 


\section{AGRADECIMENTOS}

À Faculdade de Odontologia de Ribeirão Preto da Universidade de São Paulo, na pessoa do atual Diretor Prof. Dr. Valdemar Mallet da Rocha.

À Coordenação do Curso de Pós-Graduação em Odontopediatria da Faculdade de Odontologia de Ribeirão Preto da Universidade de São Paulo, na pessoa da Prof ${ }^{a}$. Dra . Léa Assed Bezerra da Silva e do Vice-Coordenador Prof. Dr. Paulo Nelson Filho.

À minha querida orientadora Prof ${ }^{a}$. Dra. Maria Bernadete Sasso Stuani, por me aceitar como "pupila" sem nem me conhecer, por estar sempre presente nos experimentos, pela dedicação, por me ajudar, pela paciência de me ensinar e me estimular a crescer! A senhora possui um grande coração que cativa quem a cerca. Muito obrigada!

Aos Professores do Departamento de Clínica Infantil, Odontologia Preventiva e Social da Faculdade de Odontologia de Ribeirão Preto da Universidade de São Paulo Prof ${ }^{a}$. Dr . Aldevina Campos Freitas- admiro seu amor, carinho e respeito pelos pacientes, a senhora me ensinou muito; Prof. Dr. Adilson Thomazinho, Prof ${ }^{a}$. Dr ${ }^{a}$. Alexandra Mussolino de Queiroz, Prof ${ }^{a}$. Dra . Andiara de Rossi, Prof ${ }^{a}$. Dra . Dkranya Victória Díaz Serrano, Prof. Dr. Fábio Lourenço Romano, Prof. Dr. José Tarcísio Lima Ferreira, Prof ${ }^{a}$. Dra . Léa Assed Bezerra da Silva, Prof ${ }^{a}$. Dra. Maria Bernadete Sasso Stuani, Prof ${ }^{a}$. Dr ${ }^{a}$ Maria Conceição Pereira Saraiva, Prof ${ }^{a}$. Dr ${ }^{a}$. Maria Cristina Borsatto, Prof. Dr. Mário Roberto Leonardo, Prof ${ }^{a}$. Dra . Mírian Aiko Nakame Matsumoto, Prof. Dr. Paulo Nelson Filho, Prof ${ }^{a}$. Dr ${ }^{a}$. Raquel Assed Bezerra da Silva, Prof ${ }^{a}$. Dr ${ }^{a}$. Sada Assed, pela agradável convivência e grandes ensinamentos.

À Prof ${ }^{a}$. Dra . Maria José Alves da Rocha por abrir as portas de seu laboratório, permitindo que realizasse meus experimentos lá, além do auxilio intelectual.

À Prof ${ }^{a}$. Dra . Mamie Iyomasa Mizusaki e todos colegas de laboratório pela convivência.

Ao Prof. Dr. Francisco Wanderley Garcia de Paula e Silva pela amizade, pela ajuda indispensável e paciência durante o desenvolvimento deste trabalho. 
À minha querida turma de Pós-Graduação, Fernanda Regina Ribeiro Santos, Iliana Ferraz Sabbatini, Késsia Suênia Fidelis de Mesquita e Ligia Maria Napolitano Gonçalves, pelo companheirismo, amizade, aulas compartilhadas, trabalhos realizados em conjunto!

À minha amiga Maya Fernanda Manfrim Arnez, pela paciência em meus momentos agitados, pelo companheirismo, por me ajudar nos trabalhos, pelos congressos compartilhados e pelas boas risadas. Obrigada.

Aos colegas da Pós-Graduação, Denise Matos, Ana Caroline, Mariana, Bárbara, Karina, Driely, Silvana, Danielly Cunha, Danielle Lucca, Priscila, Katharina, Larissa, Alessandra Afonso, Cristhiane Bagatin, Giselle, Marta Contente, Ana Zilda, Cristina Bandão, Cristiane Rocha, Thalita, Marília, Camila, Luciane, Marcela Martim, Marcela Andrucioli, Rodrigo Valério, Rodrigo Galo, Leonardo, Fabrício, Cíntia Guimarães, Thalita, Marina Sena, Carolina Mantovani, Jaciara, Milena pelos agradáveis momentos compartilhados.

Aos Alunos do Laboratório de Neuroendocrinologia/FORP: Aline Soares, Fábio Águila, Gabriela Pelegrin, Juliana Borges, Letycia da Silva, Lucas Favaretto, Luis Henrique da Costa, Marcelo de Carvalho, Mariana Martinez, Paulo Basso, Tatiana Felippotti. Foi muito bom poder contar com vocês, pela amizade, convivência, por sempre estarem dispostos a me auxiliar!

À Técnica de Laboratório de Neuroendocrinologia/FORP Nadir Martins Fernandes pela disponibilidade, paciência e auxilio na execução da parte laboratorial deste projeto.

Aos funcionários do Departamento de Clínica Infantil, Odontologia Preventiva e Social e da Clínica de Pacientes Especiais da Faculdade de Odontologia de Ribeirão Preto da Universidade de São Paulo, Micheli Cristina Leite Rovanholo, Fátima Aparecida Jacinto Daniel, Matheus Morelli Zanela, Filomena Leli Placciti, Marco Antonio dos Santos, Nilza Letícia Magalhães, pela ótima convivência.

Aos funcionários do Biotério de Animais da Faculdade de Odontologia de Ribeirão Preto- FORP/USP, Antônio Sérgio Aparecido Mesca, Antônio Massaro e Aline 
Aparecida Ferraresi Tiballi pela disposição e ajuda durante os procedimentos experimentais e cuidados com os animais.

Aos funcionários da Seção de Pós-Graduação da Faculdade de Odontologia de Ribeirão Preto da Universidade de São Paulo, Isabel Cristina Galino Sola, Regiane Cristina Moi Sacilloto e Leandro Marin Silva, pela atenção e disposição.

À Coordenação de Aperfeiçoamento de Pessoal de Nível Superior (CAPES) pela bolsa concedida entre 2009 a 2011 e à Fundação de Amparo à Pesquisa do Estado de São Paulo (FAPESP), pelo suporte técnico, científico e financeiro, fundamentais para a realização desta pesquisa.

Aos Professores da Banca, pela atenção dispensada na leitura desta dissertação.

A todos aqueles que não foram citados, mas contribuíram de alguma forma para a realização deste trabalho. Muito obrigada! 


\section{RESUMO}

Pingueiro-Okada, E.M. Efeito do laser de baixa potência após a expansão rápida da maxila, na ativação de regiões cerebrais relacionadas à nocicepção. 2012 . 65f. Dissertação (Mestrado) - Faculdade de Odontologia de Ribeirão Preto, Universidade de São Paulo, Ribeirão Preto.

O laser de baixa potência vem sendo utilizado em Odontologia com diversos objetivos, como diminuir o tempo de reparação de tecidos moles e duros e, atualmente, alguns profissionais tem utilizado esta ferramenta para o controle clínico da dor. O presente trabalho in vivo teve como objetivo avaliar quantitativamente os efeitos do laser de baixa potência (LBP) com diodo de GaAlAs (Gálio-alumínioarsenieto) no controle da dor após a expansão rápida da maxila (ERM), analisando a ativação de regiões cerebrais relacionadas à nocicepção, por meio da expressão de c-fos nos subnúcleos caudalis, interpolaris e oralis. Utilizou-se 75 ratos Wistar, machos, pesando em média $220 \mathrm{~g}$, que foram distribuídos em 4 grupos: Grupo Controle ( $n=5)$ animais não tratados (sem ERM e sem aplicação do LBP) e no período zero foram submetidos à eutanásia; Grupo Experimental I $(n=20)$ animais submetidos apenas à aplicação do LBP no período zero e à eutanásia nos períodos 12, 2448 e 72 horas após a aplicação do LBP; Grupo Experimental II $(n=25)$ animais submetidos apenas à ERM e à eutanásia nos períodos 6, 12, 2448 e 72 horas após a ERM; Grupo Experimental III $(n=25)$ animais submetidos à ERM e logo em seguida o LBP no período zero; Os animais deste grupo foram submetidos à eutanásia nos mesmos períodos que o Grupo Experimental II. Após a eutanásia, os cérebros foram coletados e realizou-se secções coronais de 40 micrômetros. Os cortes foram processados para a imunohistoquímica para $c$-fos e analisados com o auxilio de um microscópio óptico. As células imunorreativas à proteína Fos foram contadas através do auxilio de um sistema de imagem (Image J). $O$ teste de variância (ANOVA) foi usado seguido pelo pós-teste de Tukey, com nível de significância de $5 \%$. O grupo que teve ERM apresentou um aumento significativo do número de neurônios Fos positivos nos subnúcleos interpolaris e caudalis 6 horas após a expansão maxilar, o que diminuiu expressivamente a partir de 12 horas, com um segundo pico no período de 24 horas $(p<0,001)$. $O$ grupo que teve aplicação do LBP teve redução expressiva do número de neurônios Fos positivos em todos os subnúcleos 12 horas após a aplicação da força $(p<0,001)$. Os resultados sugerem que o LBP reduz a ativação neuronal de região nociceptiva e o mesmo seria uma possível alternativa para o alívio de dor em pacientes ortodônticos.

Palavras-chave: Ortodontia; Terapia a Laser de Baixa Intensidade; Proteína c-fos; nocicepção. 


\begin{abstract}
Pingueiro-Okada, E.M. Effects of the low-level laser therapy, after experimental rapid maxillary expansion, in brain regions involved in nociception. 2012. 65f. Dissertation. Faculdade de Odontologia de Ribeirão Preto da Universidade de São Paulo, Ribeirão Preto.

Low-level laser therapy (LLLT) has been used in Dentistry with many objectives, especially to decrease the time needed for bone and soft healing. Currently, some professionals have applied this tool for clinical management of pain. The aim of the present in vivo study was to quantitatively evaluate the effects of Gallium-AluminumArsenide (GaAlAs) low-level laser therapy (LLLT) on pain control after rapid maxillary expansion (RME) in young rats, by means of $c$-fos quantification in nociceptive related structures (caudalis, interpolaris, and oralis subnuclei). A total of 75 male rats, weighting 220g, were assigned to 4 groups: Control Group $(n=5)$ with no treatment (no RME and no LLLT); Experimental I $(n=20)$ with LLLT without RME, evaluated at 12, 24, 48 and 72 hours; Experimental II $(n=25)$ with RME without LLLT, evaluated at 6, 12, 24, 48 and 72 hours after RME; Experimental III $(n=25)$ with RME and LLLT $\left(54 \mathrm{~J} / \mathrm{cm}^{2}\right)$, evaluated at $6,12,24,48$ and 72 hours after RME. The animals were euthanized, brain tissues were collected and coronal sections were cut at $40 \mu \mathrm{m}$, through the spinal trigeminal caudalis, spinal trigeminal interpolaris, and spinal trigeminal oralis subnuclei. The sections were processed for $c$-fos immunohistochemistry and were analyzed in light microscopy. The Image $\mathrm{J}$ software was used to quantify Fos immunoreactive neurons in sections of the rat brains. Statistical analysis was performed using ANOVA and Tukey tests with a significance level of $5 \%$. In the experimental group I, Fos expression significantly increased in neurons in oralis and interpolaris subnuclei 6 hours after the maxillary expansion, then significantly decreased at 12 hours, and increased again at 24 hours $(p<0.001)$. In experimental group III, Fos significantly decreased in neurons in all subnucleis 12 hours after force application $(p<0.001)$. These results suggest that LLLT decrease $c-$ fos expression in neurons of nociceptive regions and it may be used as a therapeutic alternative to reduce pain in orthodontic patients.
\end{abstract}

Keywords: Orthodontics; Low-Level Laser Therapy; Protein c-fos; Nociception. 


\section{LISTA DE ILUSTRAÇÕES}

Figura 1 - Sequência da instalação do aparelho ortodôntico entre os incisivos centrais superiores. .. 26

Figura 2 - Vista oclusal durante irradiação do LBP na sutura palatina mediana em rato.

Figura 3 - Esquema das secções coronais de cérebro de rato, evidenciando os subnúcleos oralis $(\mathrm{SpVo})$, interpolaris (SpVi) e caudalis (SpVc) nos bregmas analisados (Paxinos; Watson, 2005; modificado por Stabile, 2008).

Figura 4 - Fotomicrografias mostrando a expressão de c-fos no período de 6 horas nos grupos ERM, nos subnúcleos oralis (a), interpolaris (b), rostral caudalis (c) e caudal caudalis (d), e no grupo ERM + LBP, nos subnúcleos oralis (e), interpolaris (f), rostral caudalis $(\mathrm{g})$ e caudal caudalis $(\mathrm{h})$.

Figura 5 - Número de perfis de neurônios imunorreativos a proteínas Fos nos subnúcleos oralis, interpolaris, porção caudal do caudalis e porção rostral do caudalis em animais submetidos à irradiação com LBP. Os resultados estão expressos em média e desvio padrão. ns = não significante; ${ }^{*} p<0,5 ;{ }^{* * *} p<0,001$

Figura 6 - Número de perfis de neurônios imunorreativos a proteínas Fos nos subnúcleos oralis, interpolaris, porção caudal do caudalis e porção rostral do caudalis em animais submetidos à expansão rápida da maxila (ERM). Os resultados estão expressos em média e desvio padrão. ns = não significante; ${ }^{* *} p<0,01 ;{ }^{* * *} p<0,001$.

Figura 7 - Número de perfis de neurônios imunorreativos a proteínas Fos nos subnúcleos oralis, interpolaris, porção caudal do caudalis e porção rostral do caudalis em animais submetidos à ERM + LBP. Os resultados estão expressos em média e desvio padrão. ns $=$ não significante; ${ }^{*} p<0,05 ;{ }^{* *} p$ $<0,01^{* * *} p<0,001$.

Figura 8 - Número de perfis de neurônios imunorreativos a proteínas Fos nos subnúcleos oralis, interpolaris, porção caudal do caudalis e porção rostral do caudalis em animais submetidos à ERM e ERM + LBP. Os resultados estão expressos em média e desvio padrão. ns = não significante; ${ }^{* * *} p<$ 0,001 .

Figura 9 - Número de perfis de neurônios imunorreativos a proteínas Fos nos subnúcleos oralis, interpolaris, porção caudal do caudalis e porção rostral do caudalis em animais submetidos à ERM, LBP e ERM + LBP. Os resultados estão expressos em média e desvio padrão. ${ }^{* *} p<0,01$; ${ }^{* \star \star} p<$ 0,001 . 


\section{LISTA DE ABREVIATURAS E SIGLAS}

\begin{tabular}{ll} 
AINEs & Antiinflamatórios não esteroidais \\
ATP & Adenosina trifosfato \\
CEUA & Comissão de ética no uso de animal \\
DR & Dorsal da Raphe \\
ERM & Expansão rápida da maxila \\
FORP & Faculdade de Odontologia de Ribeirão Preto \\
GaAIAs & Gallium-aluminum-arsenide/ gálio-alumínio-arsenieto \\
HD & Hipersensibilidade dentinária \\
Laser & Light amplification by stimulated emission of radiation \\
LBP & (Amplificação da luz por emissão estimulada da radiação) \\
LC & Laser de baixa potência \\
LLLT & Locus Coeruleus \\
MPQ & Low-level laser therapy \\
PBS & McGill Pain Questionnaire \\
PAG & Solução tampão de fosfato de sódio \\
PGE & Substância Cinzenta Periaquedutal \\
RME & Prostaglandinas \\
SNC & Rapid maxillary expansion \\
TENS & Sistema Nervoso Central \\
USP & Estimulação elétrica nervosa transcutânea \\
VAS & Universidade de São Paulo \\
VRS & Visual Analogue Scales \\
& Verbal Scales \\
\hline
\end{tabular}




$\begin{array}{ll}\% & \text { Expressa um valor em percentual } \\ { }^{\circ} \mathrm{C} & \text { Graus centígrados (Celsius) } \\ \mathrm{g} & \text { Gramas } \\ \mathrm{J} & \text { Joules } \\ \mathrm{J} / \mathrm{cm}^{2} & \text { Joules por centímetro quadrado } \\ \mathrm{ml} & \text { Mililitro } \\ \mathrm{mg} / \mathrm{kg} & \text { Miligrama por quilograma } \\ \mathrm{mm} & \text { Milímetro } \\ \mathrm{mm}{ }^{2} & \text { Milímetro quadrado } \\ d p & \text { Desvio padrão } \\ p & \text { Valor- } p \\ \mathrm{pH} & \text { Potencial hidrogeniônico }\end{array}$




\section{SUMÁRIO}

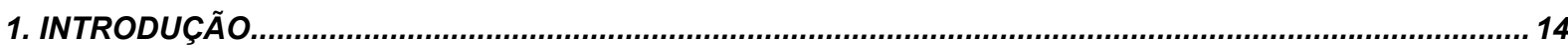

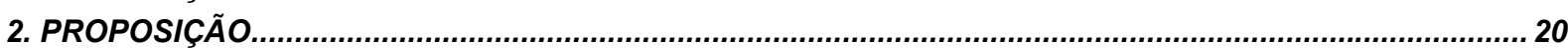

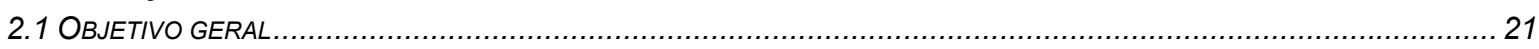

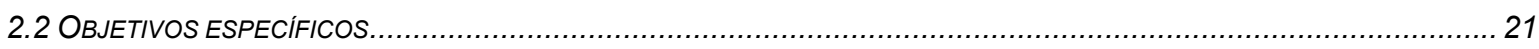

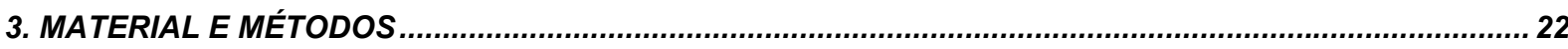

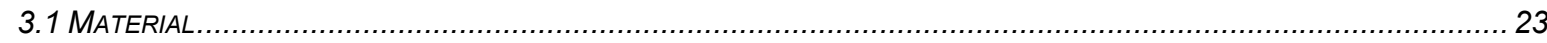

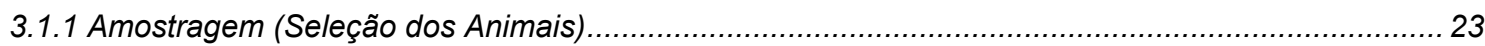

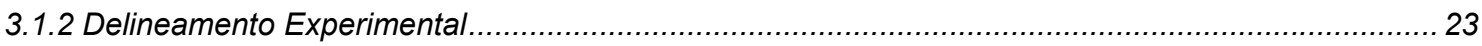

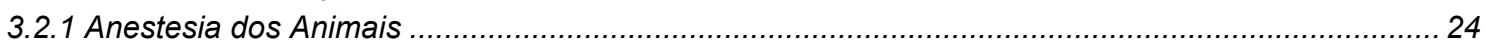

3.2.2 Instalação do Aparelho Ortodôntico para a manutenção da Expansão rápida da Sutura Palatina

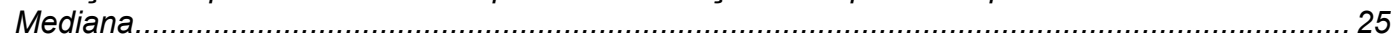

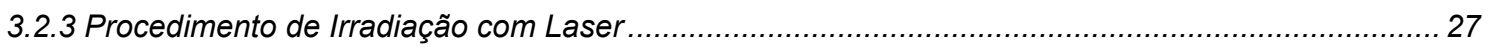

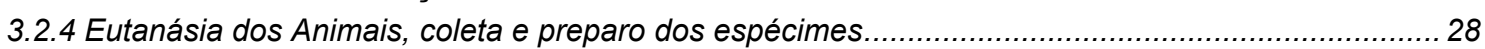

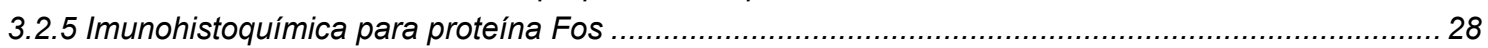

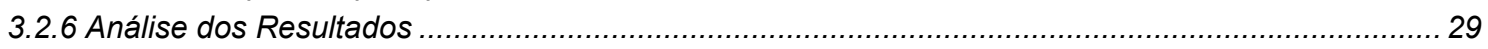

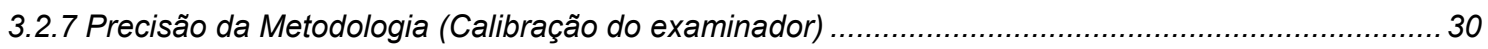

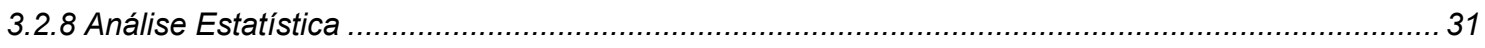

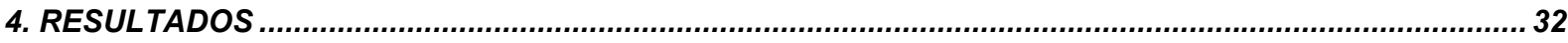

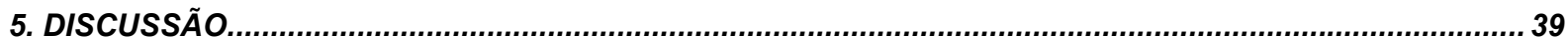

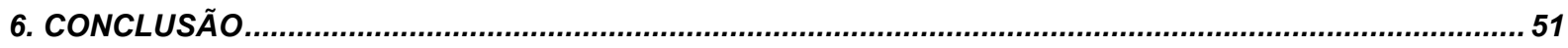

7. REFEREANCIAS

8. ANEXO 


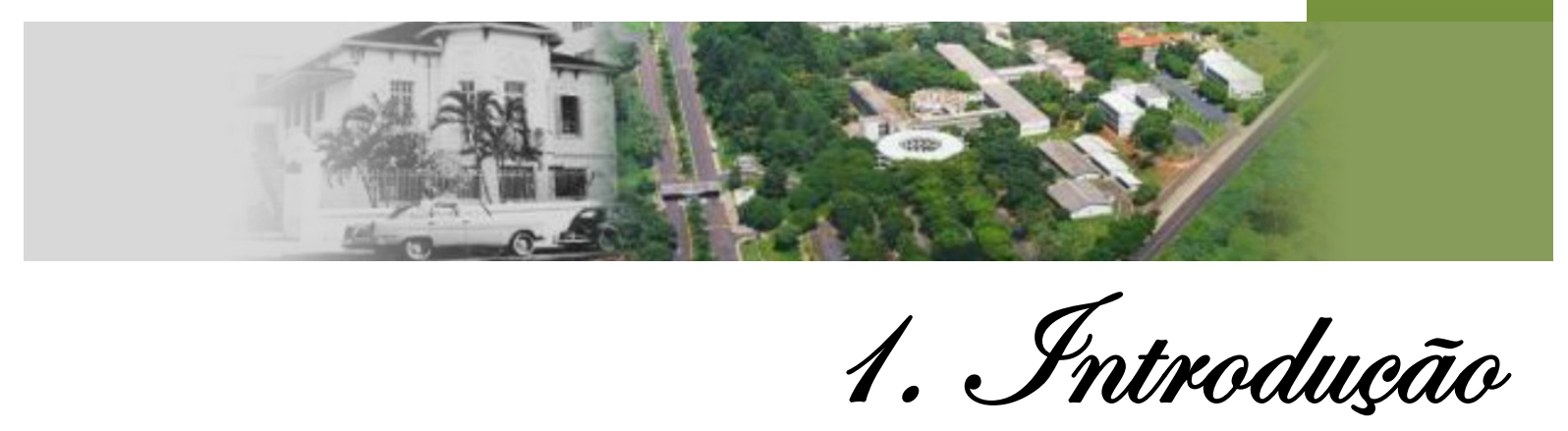




\section{INTRODUÇÃO}

A Ortodontia tem como objetivo a correção das maloclusões esquelética e dentária utilizando forças ortodôntica e ortopédica aplicadas no tecido ósseo e dentes, produzindo diversas respostas nos tecidos e consequentemente a nível celular, que resultará em remodelação do osso alveolar. A aplicação de forças ortodônticas e/ou ortopédicas causa sensações clínicas descritas como desconforto e dor (JONES, 1984; NGAN; KESS; WILSON, 1989; BROWN; MOERENHOUT, 1991). Essas sensações usualmente aparecem um dia após a aplicação da força ortodôntica, duram alguns dias e então desaparecem gradualmente (NGAN; KESS; WILSON, 1989; BROWN; MOERENHOUT, 1991). Vários estudos correlacionam essas sensações clínicas com drásticas mudanças na distribuição e formação de terminais de elementos neurais periodontais (KVINNSLAND; KVINNSLAND, 1990; KATO; WAKISAKA; KURISU, 1996; SAITO; SHIMIZU, 1997; KOBAYASHI et al., 1998). Pesquisadores observaram que essas sensações podem estar correlacionadas, experimentalmente, com alterações na atividade de neurônios do sistema nervoso central (KATO et al., 1994; YAMASHIRO et al., 1997; AIHARA et al., 1999; FUJIYOSHI et al., 2000; HIROSHIMA et al., 2001).

A presença de dor é uma experiência complexa e às vezes acompanha as consultas ortodônticas. Ela tem sido citada como efeito negativo do tratamento ortodôntico, e é de grande preocupação para os pacientes, bem como para os ortodontistas (OLIVER; KNAPMAN, 1985; KLUEMPER et al., 2002) o que está bem evidente em algumas publicações (ASHAM, 2004; KEIM, 2004). Pesquisas realizadas para determinar a experiência da dor resultante de tratamento ortodôntico mostraram que esta pode ser um impedimento para o tratamento ortodôntico e a maior razão para interromper o mesmo (HAYNES, 1974; OLIVER; KNAPMAN, 1985; BROWN; MOERENHOUT, 1991; KLUEMPER, et al., 2002; KRISHNAN, 2007). O'Connor (2000) relatou que a dor é o maior desconforto durante o tratamento ortodôntico e o quarto entre os maiores medos e apreensões prévias ao tratamento.

Sabemos que alguns procedimentos ortodônticos estão relacionados à manifestação dolorosa. Jones (1984) relatou que em estudo clínico, os pacientes tiveram desconforto nos primeiros oito dias após a colocação do aparelho otodôntico 
fixo, mas a intensidade da dor foi mais pronunciada nos primeiros três, fato observado também por Turhani et al. (2006). A maloclusão causada por um arco dental estreito, resultando em uma mordida cruzada posterior é muitas vezes tratada com expansão rápida da maxila (ERM) e este procedimento resulta em ruptura da sutura palatina mediana o que leva a um desconforto doloroso bastante intenso durante este tratamento, principalmente nos primeiros dias (TSUCHIYA et al., 1994).

Alguns pesquisadores (KATO et al., 1994; YAMASHIRO et al., 1997; AIHARA, et al., 1999; MAEDA et al., 1999; FUJIYOSHI et al., 2000; HIROSHIMA et al., 2001) observaram atividade neuronal através da expressão da proteína fos em várias estruturas cerebrais do tronco encefálico, do hipotálano e do tálamo após a movimentação dentária ortodôntica e em estudo mais recente (GAO; DUAN, 2010), observou-se ativividade neuronal através da expressão de cicloxigenase-2 (COX-2) no subnúcleo caudalis do gânglio trigeminal. Esses resultados sugerem que a informação sensorial gerada pela força ortodôntica experimental pode ser transmitida via nervos aferentes primários do ligamento periodontal às diversas estruturas do sistema nervoso central (SNC). No ligamento periodontal se encontra uma grande quantidade de terminações nervosas, que irão informar todos os pequenos movimentos dentais para o SNC. Essas terminações compreendem fibras de diâmetro grande e mielinizadas que parecem estar relacionadas com a sensibilidade tátil e fibras de diâmetro pequeno e mielinizadas ou não, que parecem estar relacionadas com a sensibilidade dolorosa. Portanto, do ligamento periodontal partem informações sobre dor e tato. Desta maneira, e junto com outros elementos nervosos do periodonto, é possível detectar e localizar, forças externas mesmo as mais delicadas sobre os dentes, bem como os deslocamentos mínimos dos elementos dentais (TRULSSON; JOHANSSON, 1996).

Os mecanorreceptores e nociceptores do ligamento periodontal que detectam tato e dor são inervados por fibras aferentes como o corpo celular ou no gânglio de Gasser ou no núcleo mesencefálico trigeminal (única exceção do corpo em que a sinapse não ocorre no gânglio, mas dentro do SNC). Ambas as terminações dos neurônios do gânglio trigeminal e do núcleo mesencefálico trigeminal são distribuídas por diferentes áreas do ligamento periodontal. Os mecanorreceptores do núcleo mesencefálico estão concentrados no ápice radicular, enquanto os mecanorreceptores trigeminais são encontrados em maior concentração no terço médio da raiz (BYERS; DONG, 1989). 
As fibras nervosas que fazem sinapse no gânglio de Gasser se dirigem para o núcleo sensorial principal, subnúcleo oralis, interpolaris e caudalis do núcleo trigeminal espinhal. Os neurônios desses dois últimos subnúcleos são ativados quando o estímulo está sendo realizado em mais de um dente, indicando convergência de impulsos para ativação dos mesmos. Já os neurônios do núcleo mesencefálico são ativados por estímulo em um único dente. Porém, durante a aplicação prolongada de uma força em um dente, esses neurônios ficam ativados somente por 10 segundos, depois são inibidos, sem que se conheça até hoje de que estrutura neural provém esse "input" inibitório (LAZAROV, 2000). Algumas sugestões envolvem o Locus Coeruleus (LC), o Dorsal da Raphe (DR) ou mesmo a Substância Cinzenta Periaquedutal (PAG), estruturas essas que alguns trabalhos revelam terem conexões com o complexo trigeminal e estarem relacionados com anti-nocicepção (KLATT et al., 1988; CRAIG, 1992; LI et al., 1993; PANNETON; JOHNSON; CHRISTENSEN, 1994; WANG; NAKAI, 1994; FEIL; HERBERT, 1995; MORGAN et al., 1997; SIMPSON et al., 1997; YAMASHIRO et al., 1997; MILLAN, 2002).

Tem sido mostrado que a estimulação térmica na polpa dentária (HU; SESSLE, 1984) estimulação mecânica no dente (COIMBRA; COIMBRA, 1994) e da membrana da mucosa oral (SUGIMOTO et al., 1994), a exposição pulpar ou extração dental (WAKISAKA et al., 1992), causam uma acentuada indução da proteína Fos nos subnúcleos do complexo trigeminal. Estudos anatômicos indicaram que a informação nociceptiva é processada para o núcleo parabraquial (HYLDEN; ANTON; NAHIN, 1989; SLUGG; LIGHT, 1994; WANG; LI; LI,, 1994; DING et al., 1995). Entretanto, os locais de processamento da informação nociceptiva originária da sutura palatina mediana após a aplicação de forças ortopédicas não foram investigadas nos subnúcleos do complexo trigeminal.

A proteína Fos, produto da expressão do proto oncogene c-fos detectada através da imunohistoquímica, tem sido usada como marcadora de atividade neuronal. Através dessa metodologia alguns pesquisadores demonstraram que os neurônios de núcleos trigeminais, do núcleo parabraquial, amígdala, paraventricular do hipotálamo e tálamo mostram imunorreatividade à proteína Fos após a aplicação de forças ortodônticas (KATO et al., 1994; YAMASHIRO et al., 1997; AIHARA, et al., 1999; MAEDA et al., 1999; FUJIYOSHI et al., 2000; HIROSHIMA et al., 2001; MAGDALENA et al., 2004). Adicionalmente esses autores mostraram que a ativação destes núcleos parece seguir uma distribuição temporal diferente com alguns 
núcleos mostrando um pico de imunorreatividade à proteína Fos após 3 horas, 24 horas ou mesmo 48 horas do início da movimentação dentária. Esses estudos foram pioneiros em estabelecer uma correlação temporal entre alterações de atividades neuronais com as sensações clínicas de desconforto e dor resultante da movimentação dentária. A movimentação dentária induzida envolve usualmente todo o arco dental e freqüentemente irá atingir outros dentes além dos molares.

Em pesquisa publicada anteriormente (MAGDALENA et al., 2004) os resultados mostraram que várias das estruturas neurais ativadas na movimentação ortodôntica de incisivos centrais superiores, são as mesmas igualmente imunorreativas à proteina Fos após movimentação dentária realizada em molares. Entretanto, os resultados foram obtidos apenas 3 horas após a colocação do aparelho, o que dificultou correlacionar temporalmente as atividades destes núcleos com as sensações clínicas descritas na literatura. Além disso, a intensidade da força utilizada produziu apenas movimentação dentária suave. Desta maneira o objetivo do presente projeto é utilizar forças de maior intensidade, normalmente utilizadas quando realizada a ERM, procedimento que produz uma maior sensação dolorosa nos pacientes, devido à abertura da sutura palatina mediana, bem como avaliar temporalmente as atividades dos núcleos do complexo trigeminal.

Quanto ao controle da dor, alguns estudos mostraram que esta foi reduzida pelo laser de baixa potência (LBP) após a retirada e colocação de arcos de fio ortodôntico, mas os resultados encontrados não foram significativos (LIM; LEW; TAY, 1995; HARAZAKI; ISSHIKI, 1997; HARAZAKI et al., 1998). A palavra laser constitui um acrônimo de origem inglesa e significa: "LIGHT AMPLIFICATION BY STIMULATED EMISSION OF RADIATION" (Amplificação da Luz por Emissão Estimulada de Radiação). Foram desenvolvidos na década de 1960, e, desde então, têm sido utilizadas para fins múltiplos. Na medicina, dois tipos de lasers são principalmente utilizados: lasers de alta e de baixa potência. O primeiro deposita alta densidade de energia no tecido irradiado e tem capacidade para cortar, coagular, e evaporar tecidos por elevar extremamente a sua temperatura. Lasers de baixa potência biomodulam tecidos irradiados, e, dependendo do tipo, intensidade, potencial, e dose, podem acelerar ou desacelerar processos fisiológico ou patológico (ABREU et al., 2010). O laser exibe três características importantes: é coerente (ondas de mesmo comprimento e em fase), bem colimado (o feixe de radiação é 
quase paralelo), e monocromático (tem o mesmo comprimento de onda, freqüência e energia) (KNAPPE, FRANK, ROHDE, 2004).

Durante as últimas décadas, o LBP tem sido utilizado para uso clínico rotineiro (BASFORD, 1986). As duas principais indicações propostas para o uso do LBP são doenças inflamatórias ou úlceras (MESTER et al., 1978; KARU, 1989) e condições dolorosas de diversos tipos (WALKER, 1983; BASFORD, 1986; HANSEN; THOROE, 1990). Os possíveis mecanismos para o efeito analgésico da irradiação do LBP sobre as estruturas cutâneas e profundas foram discutidas em vários relatos clínicos sendo sugerido que o impulso causado pela irradiação laser inibia a via aferente da dor (MEZAWA et al., 1988). Desta forma o LBP tem sido defendido como um tratamento terapêutico para uma variedade de condições, incluindo cicatrização de feridas, (MESTER et al., 1971; LYONS et al., 1987) alívio da dor e no tratamento de parestesias (WALKER, 1983). Porém a eficácia destas aplicações terapêuticas ainda permanece controversa na literatura (KHULLAR et al., 1996).

O LBP tem sido citado pelos seus efeitos bioestimulatórios em diversas situações clínicas, sendo efetivo na aceleração da cicatrização de tecidos moles e no controle de sintomatologia dolorosa crônica (MESTER; MESTER; MESTER, 1985). Em odontologia, o laser tem várias aplicações, podendo ser empregado como auxiliar terapêutico na hipersensibilidade dentinária (SGOLASTRA, et al., 2011), em lesões traumáticas da mucosa, gengivites, periodontites, pericementites, herpes simples entre outros (NANAMI et al., 1993; NEIBURGER, 1997). Por sua atuação em tecido duro e mole, acelerando a reparação óssea e a cicatrização, poderia ser utilizado em tratamento ortodôntico, cirurgia ortopédica (ABREU et al., 2010; ANGELETTI et al., 2010), após extração dental e implantes entre muitos outros procedimentos que seriam beneficiados por seu potencial bioestimulatório (SAITO; SHIMIZU, 1997; KAWASAKI; SHIMIZU, 2000). Porém, os efeitos de irradiação de laser no controle da dor, ainda apresentam poucos respaldos científicos, apesar desta ferramenta estar sendo utilizada na clínica diária, tanto na odontologia quanto na medicina.

Em relação à dor, o conhecimento do mecanismo da ação do laser nos neurônios é fundamental para que as aplicações clínicas tornem-se mais seguras e eficazes. Desta forma, outro objetivo da presente pesquisa é verificar o efeito do LBP nos neurônios, através da localização da proteína c-fos após a ERM e laserterapia, em ratos. 


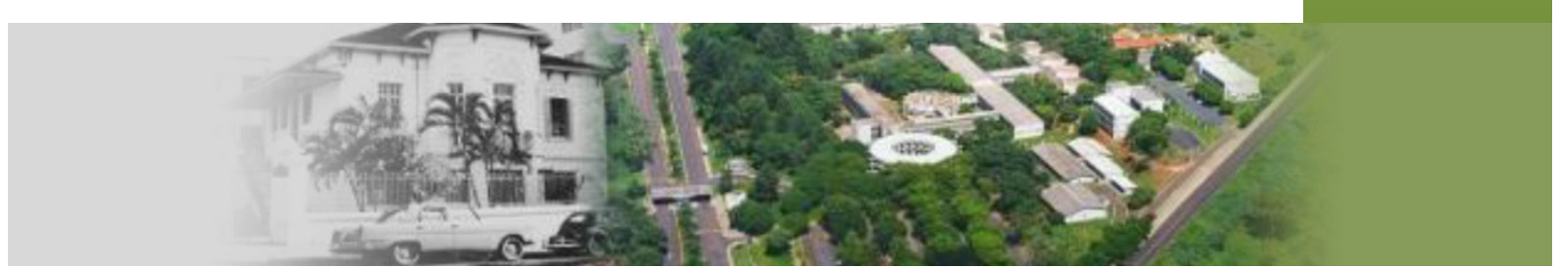

Q. Propasisaña 


\section{PROPOSIÇÃo}

\subsection{Objetivo geral}

Baseado no princípio de que a expansão rápida da maxila (ERM) é semelhante ao reparo de uma fratura (distração osteogênica), o objetivo do presente estudo foi avaliar in vivo a influência da aplicação do laser de baixa potência (LBP), usando o laser GaAIAs (Gálio-alumínio-arsenieto) sobre o controle da dor em regiões cerebrais de ratos wistar, por meio de análise imunohistoquímica.

\subsection{Objetivos específicos}

1. Verificar através da imunohistoquímica a expressão temporal de c-fos em neurônios do complexo trigeminal após a aplicação de uma força ortopédica (ERM).

2. Verificar através da imunohistoquímica, se há diferença na expressão da proteína $c$-fos entre os animais que foram irradiados com laser de baixa potência e os não irradiados. 


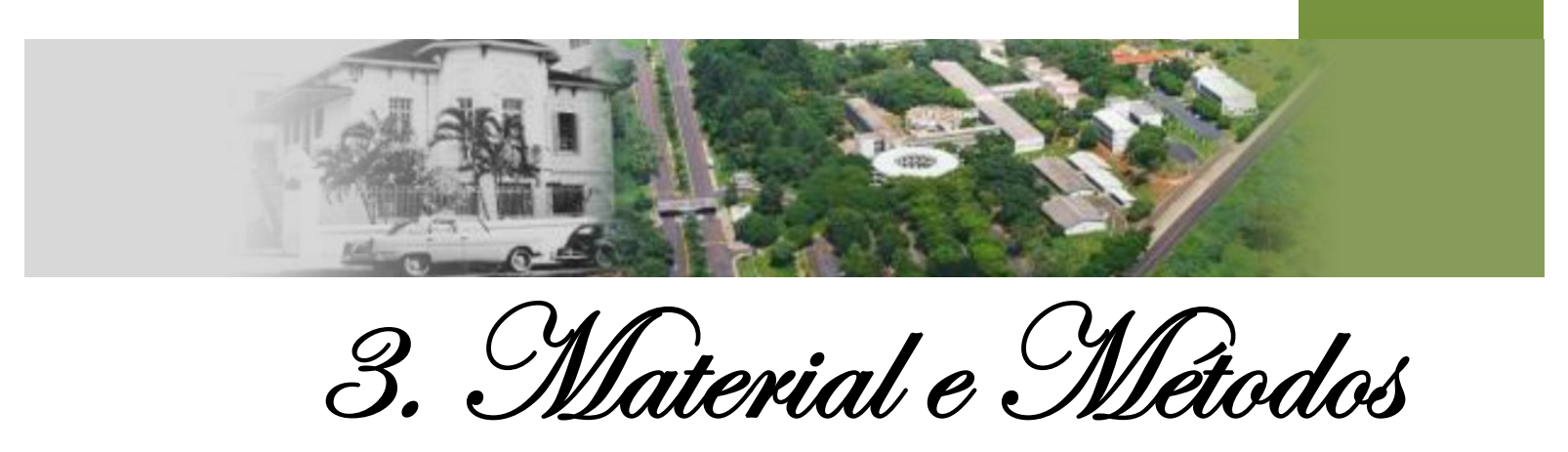




\section{MATERIAL E MÉTODOS}

\subsection{Material}

\subsubsection{Amostragem (Seleção dos Animais)}

Foram usados para este experimento um total de 75 ratos da linhagem Wistar (Rattus norvegicus, albinus), com 6 semanas de vida (jovens em desenvolvimento), pesando em média $220 \mathrm{~g}$. Os ratos foram fornecidos pelo Biotério Central do Campus Administrativo de Ribeirão Preto. Este projeto teve a aprovação da Comissão de Ética no Uso de Animais (CEUA-USP) sob protocolo 09.1.1449.53.2 (Anexo A). Durante todo o período experimental os animais foram alimentados com dieta padrão, constituída por ração moída (Nuvital®) a fim de se evitar eventuais danos ao aparelho ortodôntico durante a mastigação, e água ad libitum.

\subsubsection{Delineamento Experimental}

Para cada período experimental foram utilizados cinco animais, sendo a distribuição dos animais aleatória, nos Grupos Controle e Experimentais:

Grupo Controle: neste grupo $(n=5)$ os animais não receberam tratamento algum. Foram submetidos à eutanásia com 6 semanas de vida, no período zero.

Grupo Experimental I: neste grupo $(n=20)$ os animais foram anestesiados e receberam apenas a aplicação do LBP, sem a ERM. Esses animais foram submetidos à eutanásia 12, 24, 48 e 72 horas após o início do experimento (momento da aplicação do LBP). 
Grupo Experimental II: neste grupo $(n=25)$ os animais foram anestesiados, submetidos à ERM no primeiro dia do experimento, e à eutanásia nos períodos de 06, 12, 24, 48 e 72 horas após o início do experimento.

Grupo Experimental III: neste grupo $(n=25)$ os animais foram anestesiados, submetidos à ERM e seguida imediatamente pela aplicação do LBP. A eutanásia foi realizada nos períodos de 06, 12, 24, 48 e 72 horas após o início do experimento.

Durante o período experimental os animais permaneceram em gaiolas plásticas específicas para este fim, forradas com raspas de madeira (maravalha de pinus) e com locais apropriados para a colocação de água (ad libitum) e alimento. Cada gaiola tinha um número máximo de quatro animais. A maravalha teve a finalidade de absorver a urina dos animais e a água derramada no interior da gaiola, mantendo o fundo da gaiola-viveiro seco, substituída diariamente, fornecendo assim as condições apropriadas de higiene necessária ao bem-estar e saúde dos animais. $\mathrm{O}$ ambiente foi mantido com temperatura de $24^{\circ} \mathrm{C}$ e luz controlada (12 horas escuro/12 horas claro com luzes acesas às 6 horas), recebendo ração moída, a fim de evitar eventuais danos ao aparelho ortodôntico durante a mastigação. Foi realizada a troca diária da ração e da água, prevenindo a proliferação de fungos.

Foram selecionados apenas animais machos para eliminar qualquer variabilidade hormonal devido ao ciclo reprodutivo das fêmeas. A escolha deste animal baseou-se principalmente na disponibilidade, facilidade de manipulação, possibilidade de padronização da amostra e por ter sido utilizado em algumas pesquisas (MAGDALENA et al., 2004; STABILE et al., 2009), podendo ser aproveitadas para fins comparativos. O estado de saúde de cada rato foi avaliado por peso corpóreo diariamente monitorado por mais de uma semana antes do início da pesquisa.

\subsubsection{Anestesia dos Animais}

Durante os procedimentos, os animais foram anestesiados com $75 \mathrm{mg} / \mathrm{kg}$ Ketamina (Ketamina Agener) e 10mg/kg Xilazina (Dopaser) via intramuscular. A escolha desses anestésicos deve-se ao fato de que em trabalhos anteriores 
(ROCHA; HERBERT, 1997; MAGDALENA et al., 2004) observou-se serem os mais adequados para se estudar expressão de $c$-fos em circuitos neurais. A anestesia foi aplicada previamente à realização da ERM e instalação do dispositivo, ou aplicação do LBP, ou a associação de ambos.

\subsubsection{Instalação do Aparelho Ortodôntico para a manutenção da Expansão rápida da Sutura Palatina Mediana}

O mecanismo de força utilizado foi constituído de uma mola passiva de 1,5 $\mathrm{mm}$ de largura, confeccionada com fio de aço inoxidável de 0,5mm de diâmetro (Morelli $^{\circledR}$, Sorocaba, Brasil), colocada entre os incisivos superiores (Figura 1), semelhante ao apresentado na literatura por Sawada e Shimizu (1996), Saito e Shimizu (1997) com o intuito de possibilitar a correta calibração e padronização da separação das bordas da sutura palatina e permitir manter a expansão rápida da sutura palatina mediana.

Na montagem do aparelho para manter a ERM foram utilizados alicate $n^{0} 139$, alicate ortodôntico para corte de fio grosso (Dentaurum), espelho bucal (Duflex), sonda exploradora $\mathrm{n}^{\circ} 5$ (Duflex) e calcador de anéis (SSW). Todos os dispositivos ortodônticos foram confeccionados e instalados pelo mesmo operador e assistente, seguindo sempre o mesmo protocolo. Previamente a montagem do dispositivo, a superfície dos incisivos superiores foi preparada para aumentar a retenção e estabilizar a mola que foi fixada. Foi utilizada uma broca esférica diamantada $\mathrm{n}$ ำ1011 (K.G. Sorensen ${ }^{\circledR}$ ) em motor de alta rotação (Dabi-Atlante ${ }^{\circledR}$ ) para confeccionar ranhuras em esmalte, no terço gengival das faces vestibular e distal dos incisivos superiores. Utilizando uma espátula $\mathrm{n} \cap 7$ posicionada na sutura, entre os incisivos centrais superiores, com movimentos cuidadosos foi realizada a fratura da sutura palatina, evidenciada pela movimentação das hemi-arcadas separadamente e confirmada radiograficamente. Em seguida, realizou-se a profilaxia dos incisivos com pedra-pomes misturada com água aplicada pela taça de borracha (Viking ${ }^{\circledR}$ ) em contra-ângulo adaptado ao micromotor (Dabi- Atlante ${ }^{\circledR}$ ), por 15 segundos. Realizouse a lavagem com spray (água-ar) e a secagem com ar proveniente da seringa tríplice e condicionamento do esmalte nos incisivos utilizando ácido ortofosfórico à 
$37 \%$ em forma de gel $\left(3 \mathrm{M}^{\circledR}\right)$, durante 60 segundos, conforme recomendações do fabricante. Na sequência, foi feita, novamente, a lavagem e secagem das superfícies dentárias, por 15 segundos, com o auxílio da seringa tríplice. O agente de união (Primer e Bond 2.0 - Dentsply ${ }^{\circledR}$ ) foi aplicado sobre a superfície condicionada do esmalte e fotopolimerizado com luz halógena por 20 segundos, com auxílio do aparelho Heliomat II $\left(\right.$ Vigodent $\left.^{\circledR}\right)$. A resina fotopolimerizável (Transbond-ETM ${ }^{\circledR}$ ) foi adaptada sobre o segmento de fio nas faces vestibular e distal recobrindo-o e, em seguida foi induzida a polimerização por meio de luz halógena, com comprimento de onda de 470ๆm (Heliomat II, Vigodent ${ }^{\circledR}$ ), durante 30 segundos, dirigida em orientação oclusal, vestibular, mesial e distal de cada incisivo. Para compensar o desgaste, decorrente do contínuo hábito roedor dos animais, várias camadas de resina foram fotopolimerizadas sobre o aparelho (Figura 1).
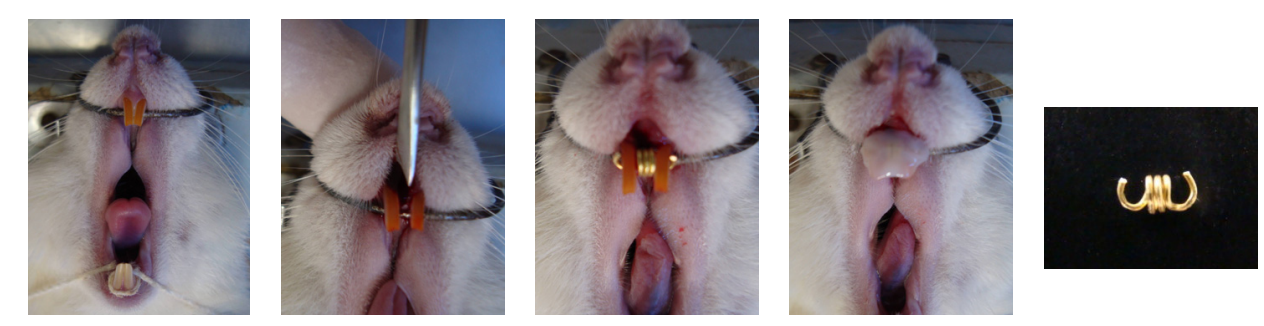

Figura 1 - Sequência da instalação do aparelho ortodôntico entre os incisivos centrais superiores.

O aparelho não recebeu ativação durante o experimento, e seu correto posicionamento foi verificado diariamente, assim como a estabilidade e necessidade de correções na eventualidade de estar causando injúrias à mucosa oral do animal. A espessura da mola de aço inoxidável foi determinada com base em resultados de um estudo preliminar (SAWADA; SHIMIZU, 1996) que indicou que 1,5mm de separação entre os incisivos induzem a taxa máxima de disjunção na sutura palatina mediana sem diminuição contínua do peso corpóreo do animal. Todos os procedimentos operatórios foram realizados na sala de Cirurgia Experimental do Biotério I da FORP-USP, em condições adequadas de higiene e pelos mesmos operadores. 


\subsubsection{Procedimento de Irradiação com Laser}

Como fonte de laser de baixa-potência, um dispositivo de laser de diodo de

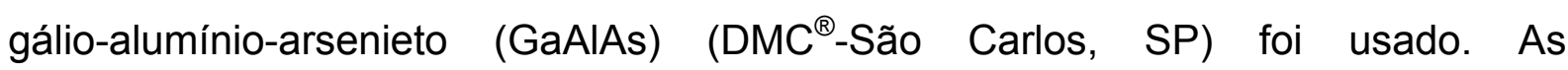
especificações técnicas deste dispositivo de laser estão demonstradas no quadro abaixo.

\begin{tabular}{|l|l|}
\hline Parâmetros de irradiação & Valores \\
\hline Densidade de Energia (DE) & $54 \mathrm{~J} / \mathrm{cm}^{2}$ \\
\hline Potência & $100 \mathrm{~mW}$ \\
\hline Comprimento de onda & $830 \eta \mathrm{m}$ \\
\hline Cor & Invisível (IV) \\
\hline Regime de emissão & Contínuo \\
\hline Área de abrangência & $0,00785 \mathrm{~mm}^{2}$ \\
\hline Distância da mucosa & Em contato/método pontual \\
\hline Tempo & 42 segundos/ponto único de aplicação \\
\hline
\end{tabular}

Quadro 1 - Protocolo de irradiação utilizado.

A ponta do laser é composta por uma fibra óptica de $0,6 \mathrm{~mm}$ de diâmetro cuja área de irradiação corresponde a $0,00785 \mathrm{~mm}^{2}$. A irradiação foi aplicada sob anestesia, colocando a extremidade da ponta da fibra óptica em contato com a mucosa palatal na linha média no ponto mediano entre as extremidades anteriores dos incisivos e papila incisiva (Figura 2).

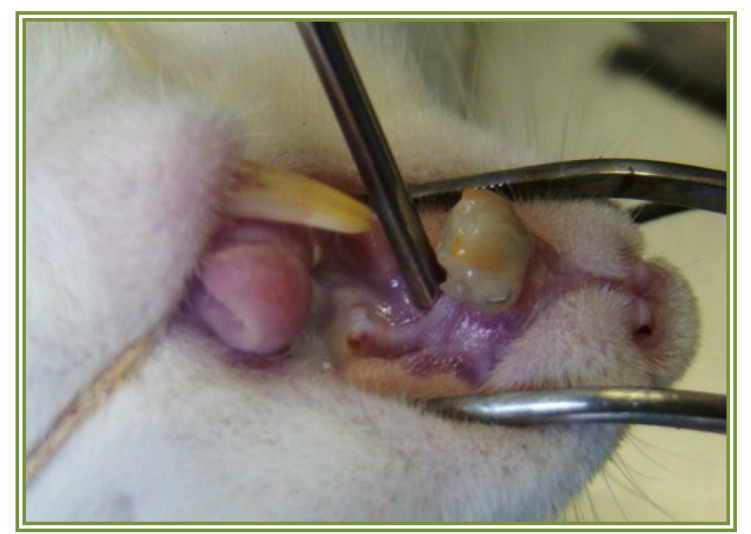

Figura 2 - Vista oclusal durante irradiação do LBP na sutura palatina mediana em rato. 


\subsubsection{Eutanásia dos Animais, coleta e preparo dos espécimes}

Ao término dos períodos experimentais, os animais foram submetidos à eutanásia por uma injeção com sobredose de anestésico com Ketamina $(100 \mathrm{mg} / \mathrm{kg})$ e Xilazina $(14 \mathrm{mg} / \mathrm{kg}$ ) via intramuscular. Os animais foram perfundidos com $50 \mathrm{ml}$ de PBS $(0,05 \mathrm{M}, \mathrm{pH} 7,4)$, seguidos de $300 \mathrm{ml}$ de Paraformaldeído 4\%, com tampão fosfato $(\mathrm{pH} \mathrm{7,4)}$. Os cérebros foram removidos e pós-fixados com o mesmo fixador por 3 horas. Em seguida os cérebros foram colocados em uma solução de PBS associada a sacarose $(30 \%)$ e mantidos até serem processados, por até no máximo de 3 dias, para imunohistoquimica para a proteína Fos.

\subsubsection{Imunohistoquímica para proteína Fos}

Secções coronais de 40 micrômetros através das regiões cerebrais estudadas foram cortadas em criostato a $-18^{\circ} \mathrm{C}$ e divididas em três séries. Uma série foi processada para imunohistoquímica e as duas restantes foram reservadas para repetições, se necessárias. Os cortes foram inicialmente lavados em tampão fosfato salina PBS $(0,01 \mathrm{M}, \mathrm{pH} 7,4)$ por aproximadamente 30 minutos. A peroxidase endógena foi bloqueada com peróxido de hidrogênio $1 \%$ em PBS por 10 minutos. Após os cortes serem lavados novamente por 30 minutos, sítios de ação inespecífica foram bloqueados durante 45 minutos por uma solução contendo soro normal de cabra diluído em PBS. A seguir foram incubados por 24 horas a 4\% com anticorpo primário policlonal de coelho antiproteína Fos (SC 52, Santa Cruz Biotechnology) diluído a 1:2000 em uma solução contendo 1\% soro albumina bovina (BSA), 0,3\% Triton X-100 (Baker, NJ, EUA) em PBS e soro normal de cabra. Após serem lavados com PBS (30 minutos) foram incubados por 90 minutos à temperatura ambiente com um anticorpo secundário, anti-lgG biotinilado de coelho, (Vectastain, Vector Laboratories) diluído em PBS. A seguir foram incubados por 30 minutos com complexo $A B$, que corresponde à solução de Avidina-Biotina- 
Peroxidase (solução A e B do kit ABC, Vectastain, Vector Laboratories). Depois de novamente lavados com PBS, o complexo AB foi revelado com 3-3' diamino benzidina $(\mathrm{DAB})$ e peróxido de hidrogênio por 3-10 min, à temperatura ambiente. A reação corou os núcleos neuronais de marrom (precipitado que marca a localização do anticorpo primário no tecido) e foi interrompida lavando-se os cortes em PBS por várias vezes. Os cortes foram montados em lâminas e deixados secar. A seguir foram desidratados em uma série graduada de álcool, diafanizados com xilol e as lâminas foram cobertas com lamínulas utilizando Entellan (Merck, KgaA, Alemanha).

\subsubsection{Análise dos Resultados}

As secções cerebrais das regiões de interesse de animais controles e experimentais foram analisadas com o auxilio de um microscópio óptico acoplado a uma câmera de vídeo (AxioCam-Carl Zeiss) e as células imunorreativas à proteína Fos foram contadas através do auxilio de um sistema de imagem utilizando o software IMAGE J 1.44p (programa de domínio público desenvolvido por Wayne Rasband NIMH, NIH, USA). Foi utilizado o Atlas (PAXINOS; WATSON, 2005) para checar a histologia cerebral e a padronização das regiões a serem fotografadas (Figura 3). Para a quantificação, foi selecionado um corte unilateral de cada núcleo no qual contam o maior número de células marcadas. Entretanto o subnúcleo caudalis, foi avaliado utilizando dois cortes (um em sua região mais caudal e outro na mais rostral), por se tratar de um subnúcleo extenso e apresentar resultados distintos. Em cada região foi padronizada uma área que era posicionada em dois lugares dentro do núcleo de interesse $\left(1 \mathrm{~mm}^{2}\right.$ cada) cobrindo mais que $50 \%$ da área de sua superfície. Cada região foi fotografada em menor aumento (5X) e em maior aumento (10X), na qual foi realizada a contagem (de duas áreas que foram previamente padronizadas). Os dados foram submetidos posteriormente ao tratamento estatístico. 


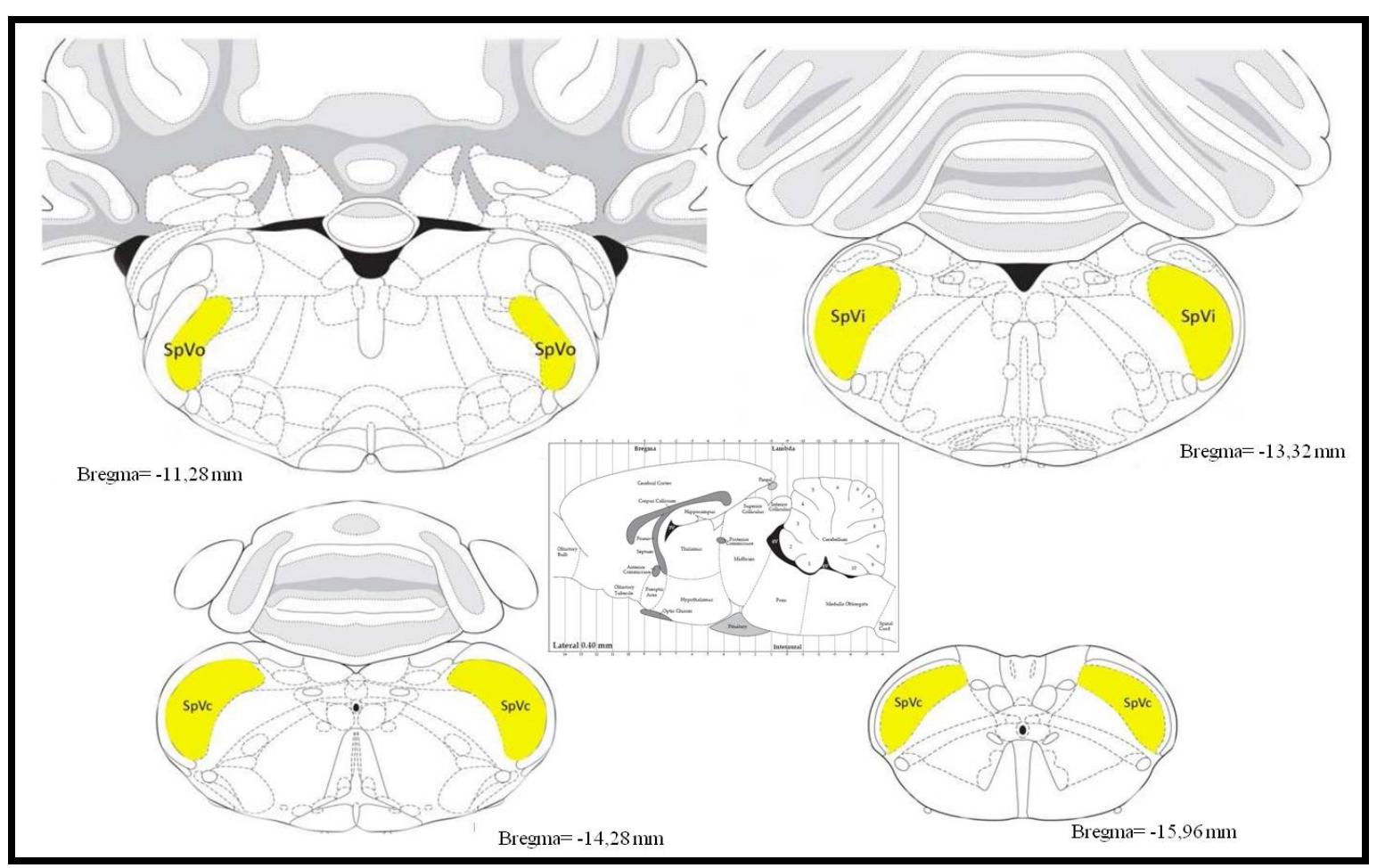

Figura 3 - Esquema das secções coronais de cérebro de rato, evidenciando os subnúcleos oralis (SpVo), interpolaris (SpVi) e caudalis (SpVc) nos bregmas analisados (Paxinos; Watson, 2005; modificado por Stabile, 2008).

\subsubsection{Precisão da Metodologia (Calibração do examinador)}

Para a confiabilidade dos resultados desse trabalho, procurou-se minimizar os erros dos métodos de mensuração empregados. Calculou-se a precisão do investigador pelo erro sistemático intraexaminador. O erro sistemático reflete uma falta de padronização do método, uma vez que o examinador tende a sub ou superestimar os valores de suas medições de maneira inconsciente, de modo a direcionar os resultados de acordo com as expectativas em relação às conclusões do estudo. Para avaliar a calibração do examinador, nas contagens, foi realizada, previamente às leituras finais, a correlação intraclasse. Vinte cortes foram aleatoriamente selecionados e suas medições foram feitas e repetidas três semanas após a primeira medição. Assim, observou-se que erros na verificação da precisão desse estudo foram admissíveis, promovendo resultados fidedignos. 


\subsubsection{Análise Estatística}

Os resultados foram agrupados de acordo com o grupo animal (tratamento recebido), período experimental (tempo), organizados em tabelas e submetidos a análise estatística.

Uma vez obtidos os dados, médias representativas de cada grupo foram submetidas a uma análise estatística com nível de significância de 5\%. Para a análise intragrupo (efeito do tempo) foi utilizado o teste paramétrico de análise de variância (One-Way ANOVA) e, quando detectada diferença estatisticamente significante, o pós-teste de Tukey foi utilizado para detectar a diferença entre os grupos dentro do mesmo ensaio. A análise intergrupo (efeito do tratamento) testou a hipótese de que a aplicação do laser de baixa potência modifica a expressão da proteína Fos por meio do teste paramétrico de análise de variância (Two-Way ANOVA) e, quando detectada diferença estatisticamente significante, o pós-teste de Tukey $(p<0.05)$ foi aplicado. Todos os testes foram realizados com o programa de estatística GraphPad Prism versão 5 (GraphPad Software Inc., San Diego, CA), tendo sido adotado o nível de significância de $5 \%$ para que as diferenças fossem consideradas estatisticamente significativas, ou seja, para rejeitar a hipótese nula. 


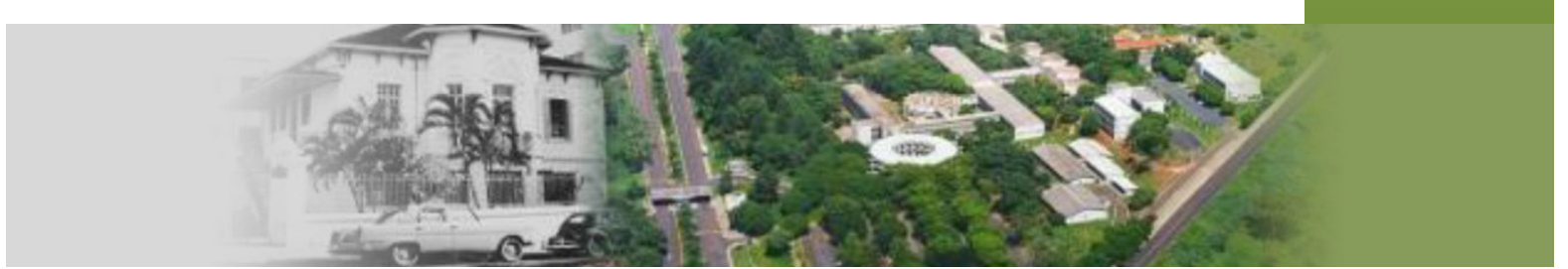

4. Oresultados 


\section{Resultados}

Os aparelhos ortodônticos foram bem tolerados por todos os grupos de animais, sem que houvesse interferências na alimentação e ingestão de água. Além disso, também não se observou variações significativas no peso dos animais durante todo o período experimental.

No grupo controle, não se observou perfis de neurônios imunorreativos a proteínas por área nas regiões estudadas.

Nos grupos experimentais foi observada expressão da proteína Fos, mais evidente no período de 6 horas. (Figura 4).
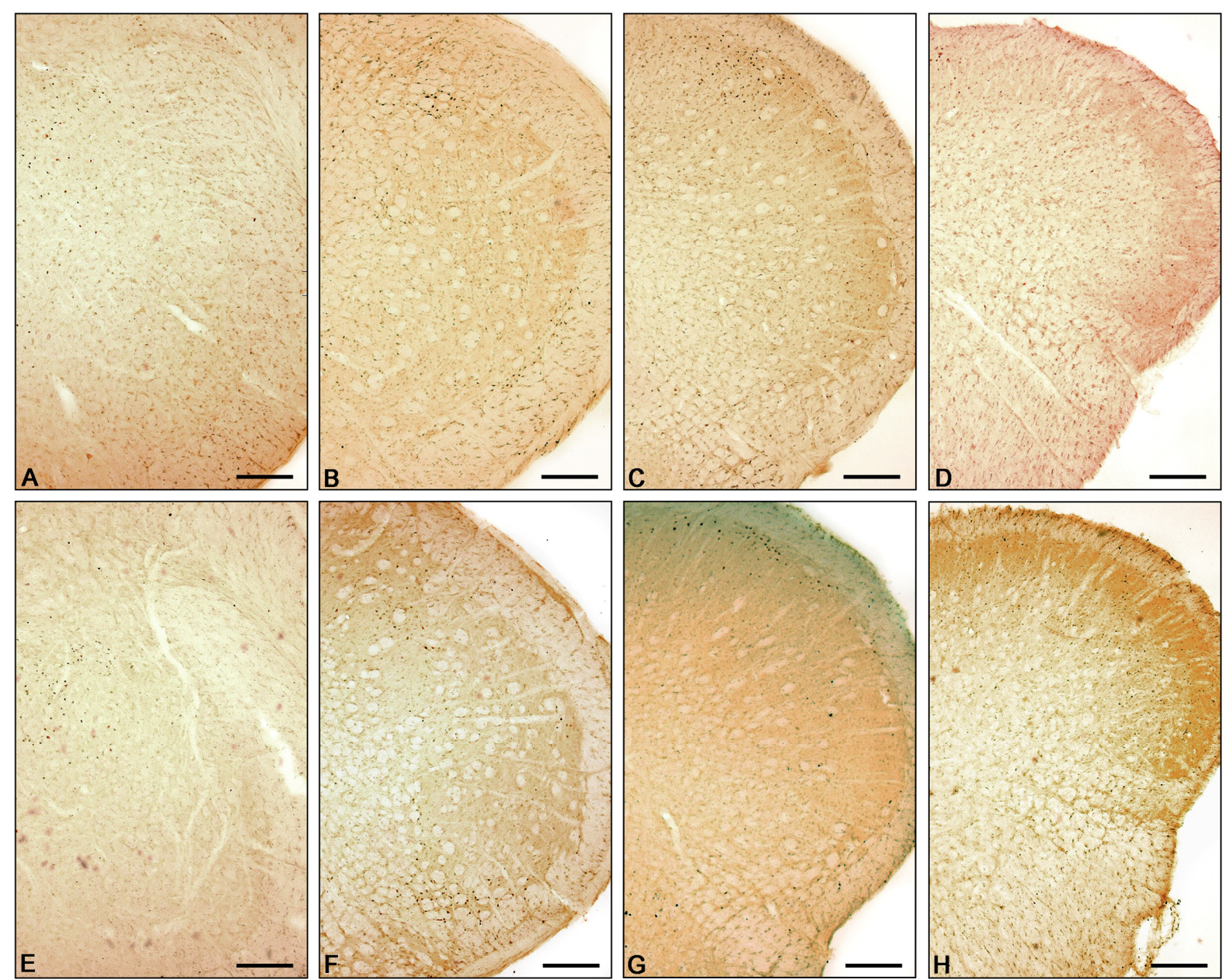

Figura 4 - Fotomicrografias mostrando a expressão de c-fos no período de 6 horas nos grupos ERM, nos subnúcleos oralis (A), interpolaris (B), rostral caudalis (C) e caudal caudalis (D), e no grupo ERM + LBP, nos subnúcleos oralis $(\mathrm{E})$, interpolaris $(\mathrm{F})$, rostral caudalis $(\mathrm{G})$ e caudal caudalis $(\mathrm{H}) .($ Barra $=200 \mu \mathrm{m})$ 


\section{A- Análise Intragrupo}

a. Grupo Experimental I: animais submetidos ao LBP

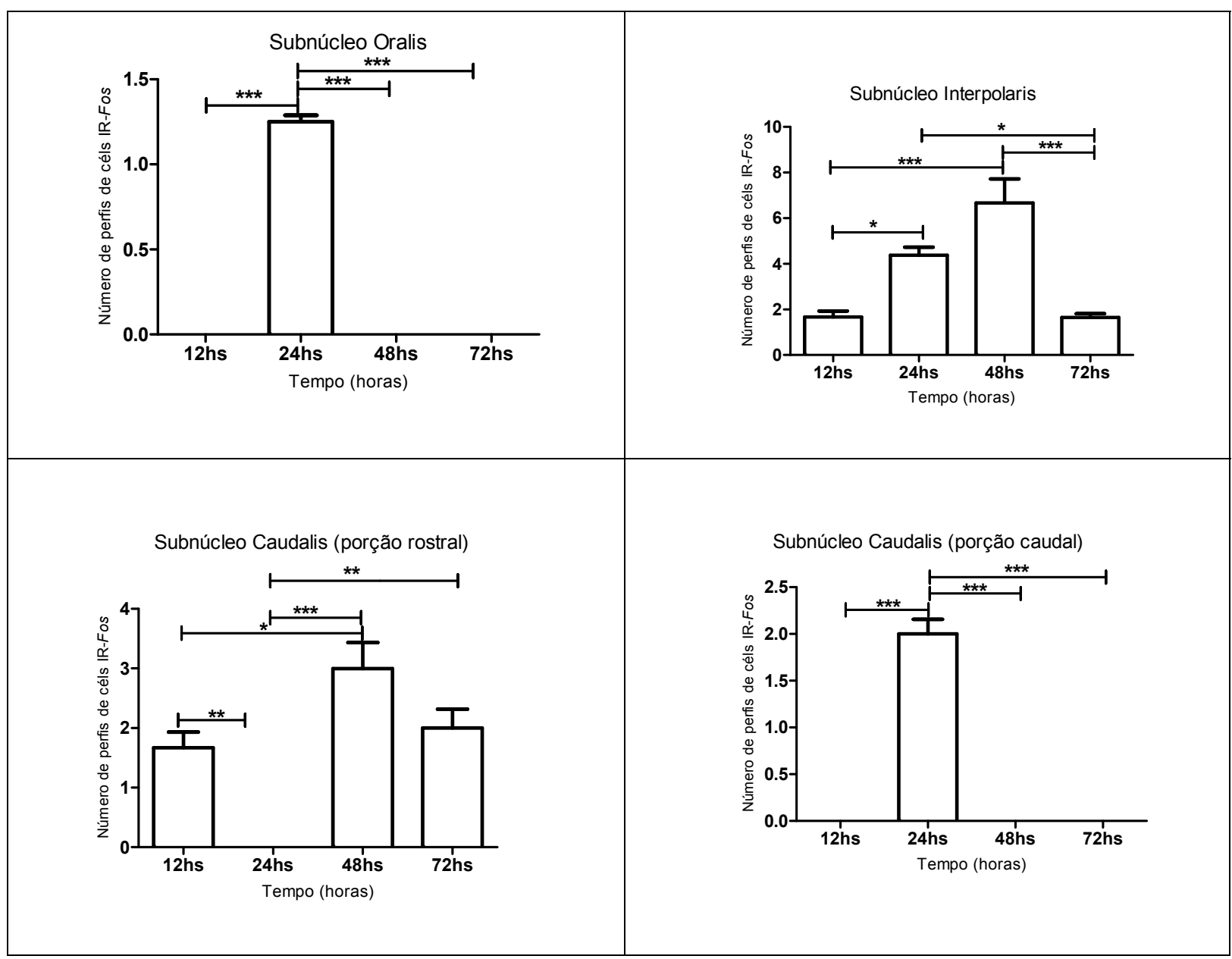

Figura 5 - Número de perfis de neurônios imunorreativos a proteínas Fos nos subnúcleos oralis, interpolaris, porção caudal do caudalis e porção rostral do caudalis em animais submetidos à irradiação com LBP. Os resultados estão expressos em média e desvio padrão. ns = não significante; ${ }^{*} p<0,5 ;{ }^{* * *} p<0,001$.

$\mathrm{Na}$ análise intragrupo, nos animais que sofreram apenas a aplicação do laser de baixa potência, observou-se uma grande variação na expressão de células imunorreativas a proteína Fos nos diferentes períodos. (Figura 5). 


\section{b. Grupo Experimental II: animais submetidos à ERM}

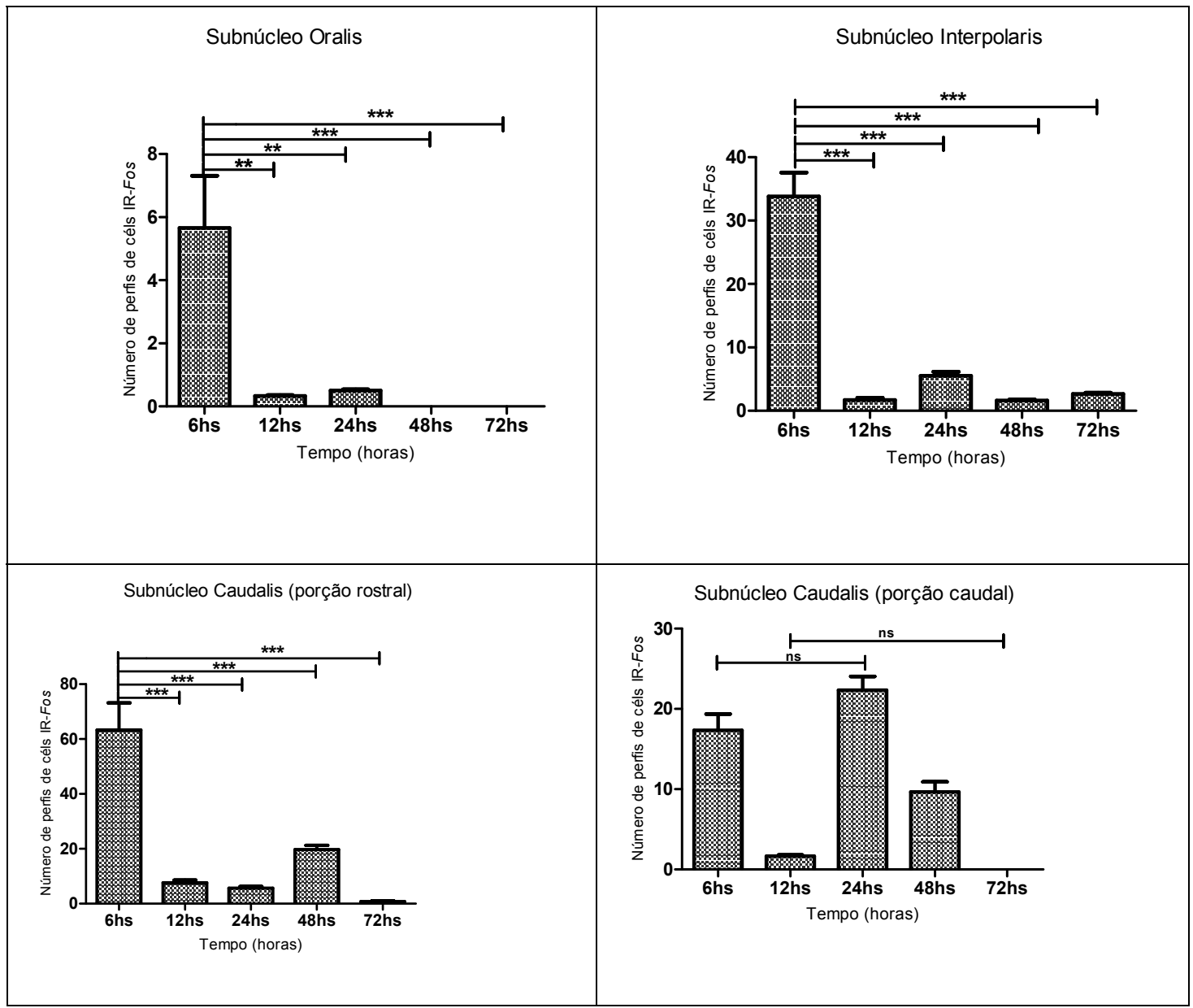

Figura 6 - Número de perfis de neurônios imunorreativos a proteínas Fos nos subnúcleos oralis, interpolaris, porção caudal do caudalis e porção rostral do caudalis em animais submetidos à expansão rápida da maxila (ERM). Os resultados estão expressos em média e desvio padrão. ns = não significante; ${ }^{* \star} p<0,01 ;{ }^{* \star *} p<0,001$.

Na análise intragrupo, a expressão de células imunorreativas a proteína Fos no subnúcleo oralis, interpolaris, porção caudal do caudalis e porção rostral do caudalis em animais submetidos à expansão rápida da maxila (ERM) mostrou uma redução acentuada partir de 12 horas até o final do experimento quando comparado com o grupo inicial (6 horas), porém apresentou um aumento da expressão às $24 \mathrm{~h}$ na porção caudal e outro aumento da expressão às $48 \mathrm{hs}$ no subnúcleo caudalis, tanto na porção rostral quanto na caudal $(p<0,001)$.

Nos animais que sofreram a ERM, a porção rostral do subnúcleo caudalis e o subnúcleo interpolaris apresentaram maior número de neurônios imunorreativos para proteína Fos $(p<0,001)$ no período de 6 horas $(63,33$ e 33,83, respectivamente), com 
menor expressão na porção caudal do subnúcleo caudalis $(17,33)$ e o subnúcleo oralis $(5,66)$. Entretanto, no período de 72 horas se observou a expressão dessa proteína. (Figura 6).

c. Grupo Experimental III: animais submetidos à ERM + LBP

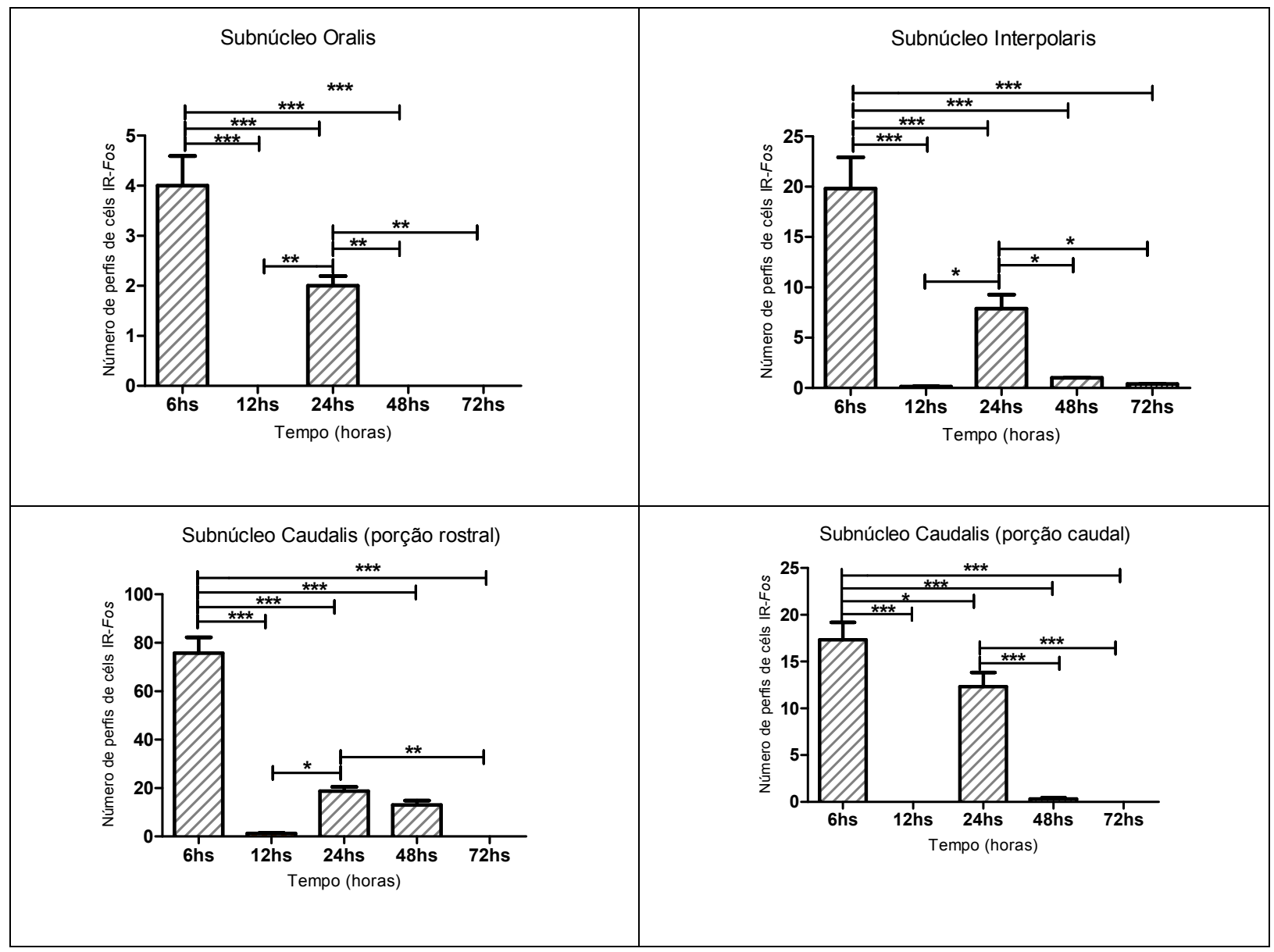

Figura 7 - Número de perfis de neurônios imunorreativos a proteínas Fos nos subnúcleos oralis, interpolaris, porção caudal do caudalis e porção rostral do caudalis em animais submetidos à ERM + LBP. Os resultados estão expressos em média e desvio padrão. ns $=$ não significante; ${ }^{*} p<0,05 ;{ }^{* *} p<0,01^{* * *} p<0,001$.

$\mathrm{Na}$ análise intragrupo, nos animais que sofreram a expansão rápida da maxila (ERM) e a aplicação do laser de baixa potência (LBP), a expressão de células imunorreativas a proteína Fos no subnúcleo oralis, interpolaris, porção caudal do caudalis e porção rostral do caudalis mostrou uma grande expressão 6 horas após a ERM (subnúcleo oralis = 4,0; interpolaris = 19,83; caudalis-rostral $=75,67$ e caudaliscaudal $=17,33(p<0,001)$. Após este período houve uma redução na expressão da proteína em todos os períodos, com um novo pico às 24 horas, porém menor que no 
início do experimento (subnúcleo oralis $=2,0$; interpolaris $=7,87$; caudalis-rostral $=$ $18,67$ e caudalis-caudal $=12,33)$. (Figura 7$)$.

\section{B- Análise Intergrupo}

\section{a. Grupo ERM e grupo ERM+ LBP}

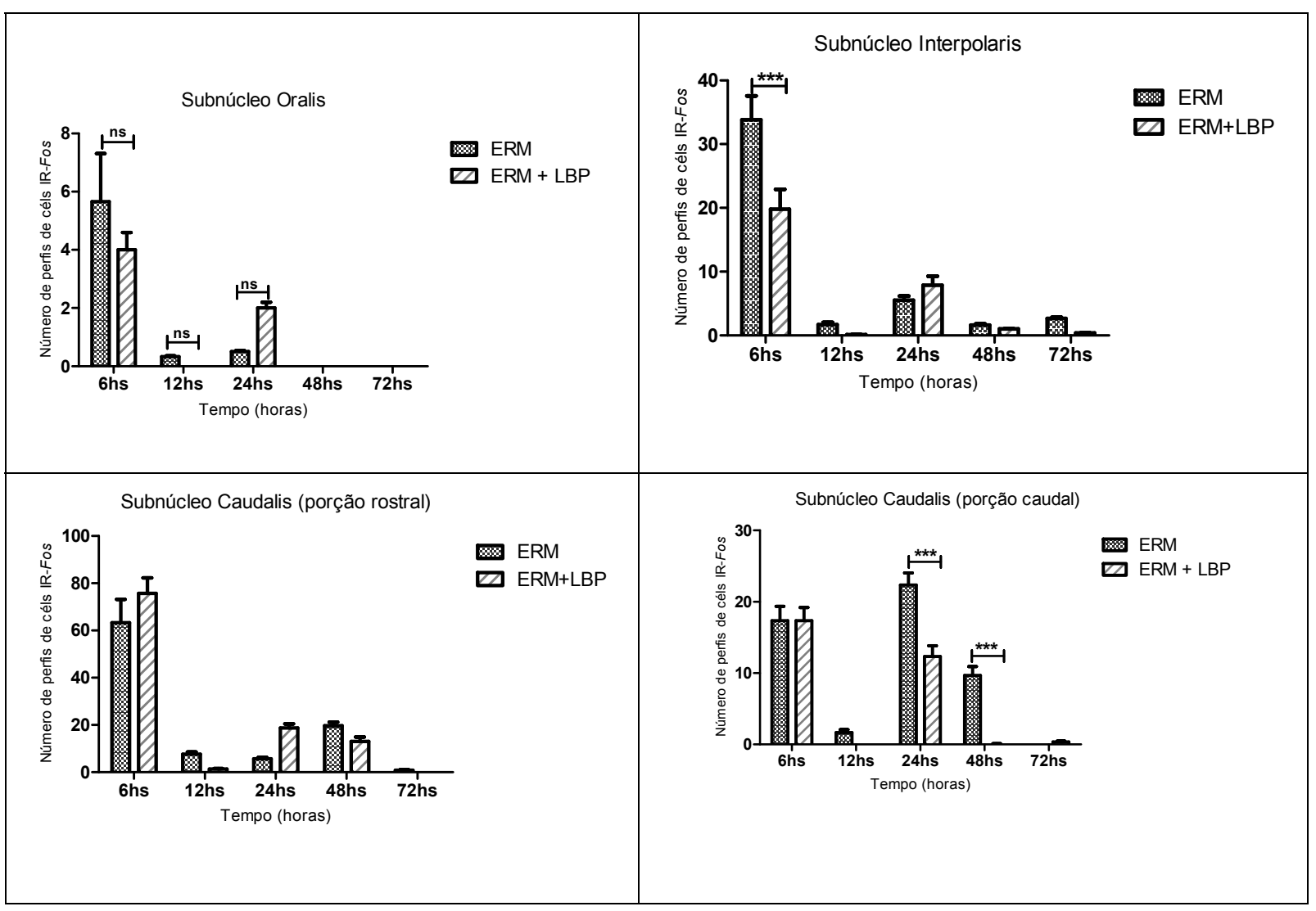

Figura 8 - Número de perfis de neurônios imunorreativos a proteínas Fos nos subnúcleos oralis, interpolaris, porção caudal do caudalis e porção rostral do caudalis em animais submetidos à ERM e ERM + LBP. Os resultados estão expressos em média e desvio padrão. ns = não significante; ${ }^{* * *} p<0,001$.

$\mathrm{Na}$ análise intergrupo, ao comparar-se os animais submetido à ERM com os animais submetidos à ERM associado ao LBP, observou-se que a expressão de células imunorreativas da proteína Fos foi significativa apenas no período de 6 horas no subnúcleo interpolaris, local onde observou-se uma redução média de 33,83 (ERM) para 19,83 (ERM + LBP). Além disso, houve uma redução significativa nos períodos de 24 e 48 horas na porção caudal do Caudalis nos grupos que tiveram laserterapia quando comparados com os que tiveram apenas a ERM. Nos outros períodos não houve diferença significativa. (Figura 8). 


\section{b. Grupo ERM, grupo ERM + LBP e grupo LBP}

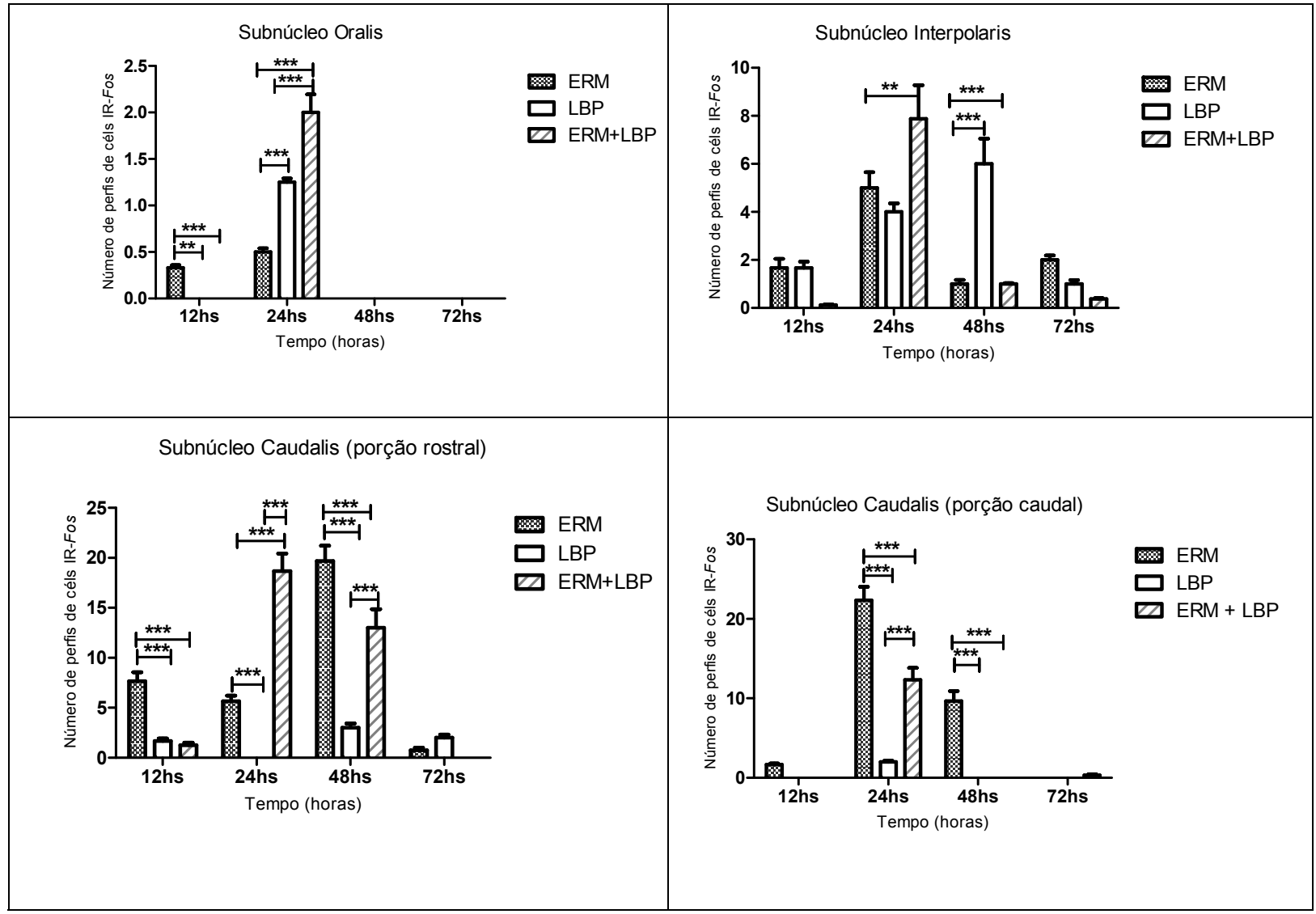

Figura 9 - Número de perfis de neurônios imunorreativos a proteínas Fos nos subnúcleos oralis, interpolaris, porção caudal do caudalis e porção rostral do caudalis em animais submetidos à ERM, LBP e ERM + LBP. Os resultados estão expressos em média e desvio padrão. ${ }^{* *} p<0,01 ;{ }^{* * *} p<0,001$.

$\mathrm{Na}$ análise intergrupo, quando compararam-se os animais que tiveram ERM, LBP e ERM + LBP no período de 12 horas, a maior expressão de neurônios imunorreativos para proteína Fos foi na porção rostral do subnúcleo Caudalis, principalmente no grupo que sofreu $\operatorname{ERM}(7,6)$ sendo que houve uma diminuição nos grupos irradiados com laser $(\mathrm{LBP}=1,67$ e ERM $+\mathrm{LBP}=1,25)$. Tal comportamento também foi observado na porção caudal do caudalis e no subnúcleo oralis. Nos outros períodos houve uma grande variação na expressão dos neurônios imunorreativos, sendo que alguns grupos, no período de 72 horas não foi observado mais imunorreatividade. (Figura 9). 


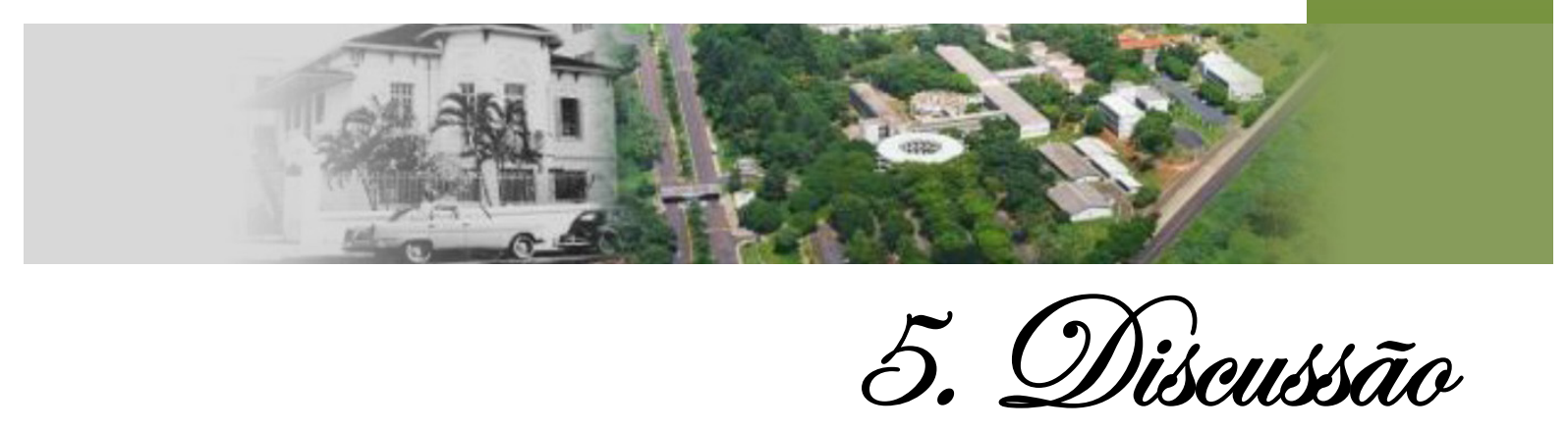




\section{DISCUSSÃO}

A dor é um sintoma clínico comum em pacientes ortodônticos nos primeiros 2 a 4 dias após a instalação de aparelhos ortodônticos fixos (SOLTIS; NAKFOOR; BOWMAN, 1971; JONES, 1984; ROTH; THRASH, 1986; NGAN; KESS; WILSON, 1989). Essa manifestação dolorosa é um dos fatores-chave que pode desencorajar o paciente a procurar um tratamento ortodôntico (OLIVER; KNAPMAN, 1985). Geralmente, os pacientes são informados de que pode haver algum desconforto associado com as manobras utilizadas durante a colocação e ajustes periódicos dos aparelhos ortodônticos. Além disso, a resposta dos pacientes para o movimento dentário resultante de forças ortodônticas é muito variável, tornando-se difícil para o ortodontista responder com precisão às expectativas dos pacientes no tocante à extensão e duração da dor (NGAN; KESS; WILSON, 1989).

Jones (1984) relatou que a dor é experimentada pela maioria dos pacientes; é mais desconfortável para adultos do que jovens, sendo verificada 4 horas após a colocação do arco ortodôntico, atinge um pico em 24 horas e depois desse período ocorre o declínio. Este estudo não considerou outras variáveis, tais como sexo, o limiar individual de dor, a magnitude da força aplicada, o estado emocional presente e stress, diferença cultural, e as experiências prévias de outros fatores que podem modificar a dor e a sensação de desconforto (NGAN; KESS; WILSON, 1989; BROWN; MOERENHOUT, 1991; SCHEURER, FIRESTONE; BURGIN, 1996; FIRESTONE; SCHEURER; BURGIN, 1999; BERGIUS, KILIARIDIS, BERGGREN, 2000; KRISHNAN, 2007). Diversos autores, que realizaram pesquisa semelhante em outros grupos raciais e étnicos, confirmaram estes resultados (NGAN; KESS; WILSON, 1989; SCHEURER, FIRESTONE; BURGIN, 1996; FIRESTONE; SCHEURER; BURGIN, 1999; ERDINC; DINCER, 2004; POLAT E KARAMAN, 2005). Desta maneira a dor geralmente dura de 2 a 3 dias e gradualmente diminui em sua intensidade no quinto ou sexto dia (NGAN; KESS; WILSON, 1989; JONES, M.; CHAN, C., 1992; JONES, M. L.; CHAN, C., 1992; BONDEMARK, FREDRIKSSON, ILROS, 2004; ERDINC; DINCER, 2004; KRISHNAN, 2007).

A causa da dor resultante do movimento dentário ortodôntico ainda não está totalmente clara. Furstman e Bernik (1972) sugeriram que a dor pode ser causada 
por um processo de pressão, isquemia, inflamação e edema (NGAN; KESS; WILSON, 1989). A força ortodôntica normalmente está relacionada a uma resposta dolorosa imediata e outra tardia. A resposta inicial à força está relacionada à compressão dos tecidos. É evidente que todos os procedimentos ortodônticos criarão zonas de tração e compressão nos tecidos, resultando numa experiência dolorosa para os pacientes. A resposta tardia está relacionada a um evento inflamatório que ocorre no tecido conjuntivo submetido às forças ortodônticas (STOREY, 1973) onde substâncias, tais como prostaglandinas (PGE), histamina, bradicinina, serotonina e substância $P$ são liberadas, o que poderia estar relacionado com o mecanismo de sensação dolorosa (FERREIRA, NAKAMURA, DE ABREU CASTRO, 1978; YAMASHIRO et al., 1997; POLAT; KARAMAN, 2005; KRISHNAN, 2007). Estudo sugere que as PGEs sensibilizam os receptores da dor, resultando em longa duração de hiperalgesia e um aumento na sensibilidade dolorosa (FERREIRA, NAKAMURA, DE ABREU CASTRO, 1978). Em um estudo o nível da substância P estava aumentado e o pico foi em 36 horas e a sua diminuição deu-se em 14 dias após a separação dos incisivos através de forças ortodônticas (KAMOGASHIRA et al., 1988). Esses dados da literatura são confirmados com os achados da presente pesquisa onde se observou um segundo pico de expressão de imunorreatividade das células neurais (24-48hs), período que a literatura mostrou haver um processo inflamatório na região sutural após a ERM, o que pode estar relacionado com os níveis altos de prostaglandinas e substância $P$, devido ao processo inflamatório na região (NGAN; KESS; WILSON, 1989). Essas alterações também podem manifestarse pelo desconforto clínico experimentado pelos pacientes após a inserção de separadores ou de arcos ortodônticos.

Sabe-se que a medição correta para expressar a dor é parte essencial da avaliação clínica, e da aplicação de métodos para controlá-la. Diversas abordagens tem sido usadas clinicamente, para medir e avaliar a percepção da dor em pacientes ortodônticos. Os métodos adotados variam de pesquisas tradicionais como o uso de questionários pré-testados, como a classificação com VAS- Visual Analogue Scales (WEWERS; LOWE, 1990), MPQ- McGill Pain Questionnaire (MELZACK, 1975) e o VRS- Verbal Scales (JONES, M.; CHAN, C., 1992; JONES, M. L.; CHAN, C., 1992; KRISHNAN, 2007). Porém, esses métodos têm suas desvantagens, como não conseguir eliminar a subjetividade do paciente, características culturais e as grandes variações individuais; motivos pelos quais se utilizar experimentos em animais a fim 
de comprovar esta sensação manifestada pelos pacientes. Em estudo animais, a expressão da proteína Fos é um dos modelos de pesquisa utilizados como marcador de atividade fisiológica neuronal $\mathrm{e}$ as vias neuronais específicas no cérebro (SAGAR; SHARP; CURRAN, 1988; DRAGUNOW; FAULL, 1989; STABILE et al., 2009). O c-fos é um protooncogene da classe dos genes de ativação imediata e codifica a proteína Fos, a qual é um fator indutor de transcrição (CURRAN; MORGAN, 1987). A expressão de proteína Fos se dá em decorrência dos mais diversos estímulos, como por exemplo, a despolarização de neurônios (CURRAN; MORGAN, 1987), estresse (TITZE-DE-ALMEIDA et al., 1994), e nocicepção (HUNT; PINI; EVAN, 1987; HARRIS, 1996), e esta expressão começa em cerca de uma a duas horas após o início do estímulo (HUNT; PINI; EVAN, 1987).

Foi demonstrado que a movimentação dentária experimental induz a expressão de c-fos no complexo trigeminal sensorial (KATO et al., 1994; MAGDALENA et al., 2004). A expressão proteica apareceu de 2 a 4 horas após o início da movimentação dentária, indicando que a nocicepção pode estar relacionada com a compressão do ligamento periodontal imediatamente após a aplicação da força nos dentes e os estímulos não intencionais na cavidade oral, associados ao procedimento experimental. Entretanto, a observação clínica demonstra que a dor e o desconforto geralmente perduram por até 3 dias após a aplicação de forças ortodônticas (YAMASHIRO et al., 1997).

O núcleo espinhal do trigêmio se divide em três subnúcleos, no sentido rostrocaudal: oralis, interpolaris e caudalis (TAKEMURA et al., 2006). O subnúcleo caudalis é um importante centro de retransmissão de informações nociceptivas de estruturas orofaciais, incluindo os dentes (SESSLE, 2000). A região localizada acima do obex, que inclui os subnúcleos interpolaris e oralis, é caracterizada por receber informações dos ramos trigeminais que inervam a cavidade oral, recebendo aferências da polpa dental além de cutâneas e mucosas (FUJIYOSHI et al., 2000; TAKEMURA et al., 2006). Desses núcleos, as informações são transmitidas para regiões mais superiores do cérebro, como o tálamo posterior, para que sejam processadas (TAKEMURA et al., 2006). As alterações no SNC, promovidas pela movimentação dentária, foram pesquisadas através da expressão da proteína Fos no núcleo espinhal do trigêmio (MAGDALENA et al., 2004).

Nos últimos anos vem aumentando o número de pacientes com maloclusões causadas pela maxila atrésica (estreita) na clínica ortodôntica. O tratamento dessa 
maloclusão se faz com a expansão rápida da maxila (ERM), ou seja, com o alargamento da arcada dentária superior. Este procedimento resulta na aplicação de forças de magnitude elevadas sobre o complexo maxilo-facial, produz uma série de reações no tecido conjuntivo sutural e periodontal caracterizada por deslocamento, deformação e desenvolvimento de estresse interno (MAO, 2002; MAO; WANG; KOPHER, 2003) e processo inflamatório com liberação de substâncias como as PGs. Ten Cate et al. (1977), após exercer uma força de expansão sagital em ratos, observou ferimento traumático, exsudato, morte de fibroblastos, rompimento das fibras colágenas e inflamação aguda. Como parte do processo inflamatório, o paciente percebe uma sensação dolorosa, que é diversas vezes expressa em toda região craniofacial. Existem relatos na literatura que é comum os pacientes queixarem-se de dor após a aplicação de forças ortopédicas para a ERM, não apenas durante a abertura da sutura, como também alguns dias após a mesma (HANDELMAN, 1997; NEEDLEMAN et al., 2000; SCHUSTER, BOREL-SCHERF, SCHOPF, 2005). Needleman et al. (2000) afirmou que a grande maioria das crianças submetidas à ERM teve experiência de dor, que ocorreu durante a fase inicial e diminuiu gradativamente (KRISHNAN, 2007). É bastante comum os pacientes submetidos à ERM relatarem um desconforto doloroso maior do que a simples aplicação de força ortodôntica aos dentes, pois esse procedimento além de aplicar forças aos dentes, provoca uma separação à nível sutural. Sabendo-se que uma maior força aplicada promove maior isquemia tecidual e, consequentemente, maior reação inflamatória no tecido conjuntivo (SAITO et al., 1991; SANDY; FARNDALE; MEIKLE, 1993; GRIEVE et al., 1994; KRISHNAN, 2007; STABILE, 2008) o presente trabalho utilizou forças ortopédicas, que foram eficazes em promover a separação da sutura palatina mediana, semelhante à realizada em humanos, a fim de verificar a influência desse estímulo na expressão de proteína Fos nos subnúcleos cerebrais.

A correlação entre a ativação das células cerebrais e sensação clínica de dor e desconforto durante o movimento ortodôntico é uma questão de interesse clínico. A expressão e a distribuição de c-fos além de ser avaliada no núcleo sensorial do complexo trigeminal, tem sido demonstrada em outras regiões, como núcleo parabranquial, núcleo paraventricular do hipotálamo e tálamo, (KATO, WAKISAKA, KURISU, 1996; YAMASHIRO et al., 1998; AIHARA, et al., 1999; MAEDA et al., 1999; FUJIYOSHI et al., 2000; HIROSHIMA et al., 2001). 
A literatura demonstra que há expressão de $c$-fos no subnúcleo caudalis após a indução de movimentação dentária em molares de ratos, com prevalência na região próxima ao obex e no lado ipsilateral ao estímulo (KATO et al., 1994; YAMASHIRO et al., 1997; AIHARA, et al., 1999; MAEDA et al., 1999; FUJIYOSHI et al., 2000). Na presente pesquisa os resultados foram similares, a ERM também foi eficaz em induzir a expressão de c-fos no subnúcleo caudalis, mas em ambos os lados do subnúcleo, o que pode ser relacionado à forma do aparelho utilizado, que aplicou forças nas maxilas direita e esquerda ao mesmo tempo, fato também relatado em outras pesquisas (MAGDALENA et al., 2004, STABILE et al., 2009). A avaliação temporal da expressão de $c$-fos neste mesmo subnúcleo mostrou picos de atividade nas seis horas que se seguiram ao estímulo, diminuindo após 12 horas e aumentando novamente em 48 horas, desta vez em menor intensidade, com nova queda em 72 horas, fato também observado em outros trabalhos que utilizaram forças de menor magnitude (KATO et al., 1994; FUJIYOSHI et al., 2000).

Fujiyoshi et al. (2000) encontraram expressão de c-fos no subnúcleo oralis, mas esta se mostrou de pouca intensidade nas primeiras 12 horas de estímulo, tendo aumentado em 24 horas, com pico de expressão em 48 horas e declínio em 72 horas. No presente estudo, após a ERM houve expressão da proteína Fos no subnúcleo oralis e interpolaris no período de 6 horas, com posterior declínio. Todavia, Kato et al. (1994) não encontraram expressão de c-fos no subnúcleo caudalis, tampouco no subnúcleo interpolaris, nos períodos que avaliaram, os quais foram até 24 horas após a indução da movimentação dentária.

Nossos resultados indicam que a abertura da sutura palatina mediana, causada pelo ato cirúrgico e mantida pelo aparelho utilizado, evocou a nocicepção. Em avaliação posterior, observou-se que os neurônios marcados para c-fos estavam localizados, principalmente, nas lâminas superficiais (lâmina I e II) nas bordas dorsomedial e ventral, predominantemente perto do ápice e também na zona de transição para o interpolaris. Esta lâmina superficial é conhecida por conter neurônios nociceptivos específicos. (HU; SESSLE, 1984; BESTER et al., 1997; JASMIN et al., 1997). Isto foi confirmado pelos achados de redução na expressão destes neurônios em pacientes submetidos a um pré-tratamento com morfina (AIHARA, et al., 1999; MAEDA et al., 1999). Além disso, a naloxona (antagonista da morfina), reverteu esse efeito (HIROSHIMA et al., 2001; KRISHNAN, 2007). 
Baseados nessas informações, escolheu-se os subnúcleos oralis, interpolaris e caudalis para verificar a expressão de c-fos após a ERM.

No presente estudo, a expressão de $c$-fos foi maior nas regiões marginais do subnúcleo caudalis do ganglio trigeminal. O padrão de expressão foi semelhante, àquelas induzidas por estimulação térmica da polpa dental (HU; SESSLE, 1984), estimulação mecânica da membrana da mucosa oral (SUGIMOTO et al., 1994), exposição pulpar ou extração dental (WAKISAKA et al., 1992). Os resultados indicam que a ERM experimental induz a nocicepção na região sutural e esta informação nociceptiva periférica poderia acabar no subnúcleo caudalis do gânglio trigeminal.

O estímulo também provocou a expressão de $c$-fos no subnúcleo interpolaris. A região do núcleo principal do trigêmio que se localiza acima do obex, na qual se inclui o subnúcleo interpolaris e está relacionada à sensibilidade nociceptiva intrabucal, recebendo estímulos do tecido pulpar e da mucosa bucal (SHIMIZU et al., 2006; TAKEMURA et al., 2006; STABILE, 2008). A mucosa oral possui uma solução de continuidade com o tecido conjuntivo sutural, que provavelmente foi sensibilizada pela força aplicada, devido ao íntimo contato de suas fibras nervosas com o tecido conjuntivo. Contudo, trabalhos que aplicaram movimentação dentária em ratos, usando metodologias diversas, tiveram resultados conflitantes na expressão de $c$-fos no subnúcleo interpolaris (KATO et al., 1994; YAMASHIRO et al., 1997; JOVILIANO et al., 2008). Enquanto Kato et al. (1994) e Yamashiro et al. (1997) não encontraram aumento no número de neurônios Fos positivos neste subnúcleo, após movimentação dentária em molares de ratos, Joviliano et al. (2008) observou picos de expressão de c-fos em 6 e 48 horas após a aplicação de $70 \mathrm{~g}$ de força em incisivos também de ratos, fato também observado na presente pesquisa. Uma maior força aplicada promove maior reação inflamatória (WALDO; ROTHBLATT, 1954; FURSTMAN; BERNICK, 1972; SAITO et al., 1991; KRISHNAN, 2007) e os mediadores inflamatórios, como as PGs, poderiam facilitar a ativação de fibras nervosas que vão para este subnúcleo, levando aos resultados encontrados por Joviliano (2006). O presente experimento, por ter usado maior magnitude de força para obter a separação da sutura palatina mediana, produziu maior inflamação no tecido sutural, o que fez com que os resultados evidenciassem alterações na expressão da proteína Fos neste sub-núcleo, corroborando com os resultados de Joviliano (2006). 
A presença de c-fos nas primeiras horas após a estimulação ortodôntica pode ser relacionada à ativação direta dos nociceptores do tecido conjuntivo sutural, em decorrência da compressão dos tecidos pela força aplicada, e a expressão tardia à reação inflamatória instalada, a qual é responsável pela remodelação óssea na região, o que foi demonstrado na literatura quando se aplicou forças ortodônticas suaves (FUJIYOSHI et al., 2000). Reforça esta teoria o fato de que os níveis de PGs e outros mediadores inflamatórios não se mostram alterados, após o estímulo ortodôntico (KRISHNAN, 2007) e que as manifestações clínicas de dor, observadas nos pacientes após a ativação do aparelho ortodôntico, seguem sequência cronológica parecida com a da expressão de $c$-fos, encontrada nos experimentos com ratos (BROWN; MOERENHOUT, 1991; JONES, M.; CHAN, C., 1992; FUJIYOSHI et al., 2000; ERDINC; DINCER, 2004; KRISHNAN, 2007).

No grupo que teve apenas ERM a expressão de c-fos foi intensa imediatamente após o trauma ortopédico, (6 horas após o início da ERM) e apresentou um novo pico 24 horas após a aplicação da força e ainda perdurou até às 48 horas em todos os subnúcleos. Estudos anteriores que utilizaram a movimentação dentária induzida mostraram um padrão da expressão do c-fos semelhante no subnúcleo caudalis do trigêmio após 1, 2 e 4 horas; no entanto, a expressão não foi detectada após 24 horas (KATO et al., 1994). Esta discrepância pode estar relacionada com a sensibilidade da técnica utilizada para detectar a proteína c-fos e também da magnitude da força utilizada. Quando uma força mecânica é aplicada aos dentes durante um período prolongado, um evento inflamatório ocorre dentro do espaço periodontal (STOREY, 1973). Desta forma, a nocicepção no presente estudo pode ter sido provocada pela resposta inflamatória induzida mecanicamente e a sensação dolorosa depois diminui, provavelmente porque o processo inflamatório inicial esta sendo removido da região. Estes dados estão de acordo com os relatos clínicos de desconforto manifestado pelos pacientes.

Considerando esses dados, pode-se sugerir que uma terapia analgésica eficaz para o tratamento ortodôntico deve durar, em alguns casos, ao menos as 48 horas que se seguem à ativação do aparelho ortodôntico. As tentativas para controlar a dor durante 0 tratamento ortodôntico abrangem muitas modalidades. Aparelhos ortodônticos são projetados com os fios mais leves que proporcionam menos força para os dentes, porém é comum alguns profissionais indicarem analgésicos e agentes anti-inflamatórios não-esteroidais (AINEs) a seus pacientes. A grande 
preocupação em relação AINEs é a interferência produzida sobre a inflamação associada com o processo de movimentação dental. Trabalho recente verificou que a administração de celecoxib e acetaminofeno por um ou dois dias nos estágios iniciais do movimento dentário não afetou o processo de movimentação dentária (STABILE et al., 2009). A tendência atual está direcionada para uso de analgésicos pré-operatórios, os quais são administrados, pelo menos, uma hora antes de cada procedimento ortodôntico (KRISHNAN, 2007). A utilização da estimulação elétrica nervosa transcutânea (TENS) tem mostrado promessa para alívio da dor (ROTH; THRASH, 1986). O uso do laser de baixa potência (LBP) é outra modalidade que vem sendo utilizada para controlar a dor. É essencial que o controle da dor durante o tratamento ortodôntico seja considerado como um aspecto importante da mecanoterapia ortodôntica e que esta modalidade de tratamento seja avaliada sistematicamente.

Com o advento da laserterapia principalmente estimulando a formação óssea e a vascularização, tal recurso tem sido utilizado na odontologia acelerando dessa forma a proliferação vascular e celular, mostrando assim ser um potencial recurso a ser utilizado na clínica diária. Dessa forma, alguns profissionais passaram a utilizar esta ferramenta para o controle da dor. Lim, Lew e Tay (1995) em uma avaliação clínica da eficácia da terapia do LBP na redução da dor resultante do tratamento ortodôntico encontraram resultados desanimadores e não foi encontrado alívio imediato da dor em pacientes ortodônticos. Porém, a maioria dos trabalhos publicados recentemente são experimentos clínicos subjetivos sem uma comprovação científica para tal, ficando dessa forma difícil relacionar o controle da dor com a laserterapia (KRISHNAN, 2007). Para encontrar alternativas para o alívio da dor, pesquisadores investigaram o LBP no uso clínico (LIM; LEW; TAY, 1995; HARAZAKI; ISSHIKI, 1997; HARAZAKI et al., 1998). A literatura demonstrou que o LBP tem sido utilizado para o tratamento de vários tipos de dor, como dor inflamatória (GOLDMAN, et al., 1980; MARCOS et al., 2011), dor crônica (WALKER, 1983; AY, DOGAN, EVCIK, 2010), hipersensibilidade dentinária (SGOLASTRA et al., 2011), neuralgia do trigêmeo (WALKER, 1983; BASFORD, 1989), ciático (TSUCHIYA et al., 1994; BERTOLINI et al., 2011).

Os dois tipos de laser mais comuns usados atualmente para tais tratamentos são os de luz vermelha como o de Hélio-Neônio (comprimento de onda, perto de $630 \eta \mathrm{m}$ ) e o diôdo infravermelho (comprimento de onda, perto de $830 \eta \mathrm{m}$ ) 
(TSUCHIYA et al., 1994). De acordo com algumas pesquisas, estes podem inibir as respostas à dor em vias nociceptivas em terminais sensoriais periféricos (ITO et al., 1989; HONMURA et al., 1992), conduzindo ao longo de nervos sensoriais (MEZAWA et al., 1988; TSUCHIYA et al., 1993) e/ou na medula espinhal ou outros neurônios centrais (ZARKOVIC et al., 1989; TSUCHIYA et al., 1994). Porém, as recomendações são baseadas principalmente em experiências clínicas positivas em vez de clássicos ensaios clínicos placebo-controle. Sgolastra et al. (2011), em uma revisão sistemática da eficácia do tratamento com laser na redução da hipersensibilidade dentinária (HD), verificaram apenas 3 estudos clínicos randomizados e destes, a redução da HD não foi significativa em comparação com o tratamento a laser e o placebo. Alguns trabalhos (WALKER, 1983; SNYDERMACKLER et al., 1986) indicam resultados positivos no tratamento da dor, enquanto que diversos estudos não mostram qualquer diferença entre o tratamento com o laser e o placebo (BASFORD et al., 1987; JENSEN; HARREBY; KJER, 1987; LUNDEBERG; HAKER; THOMAS, 1987; WAYLONIS et al., 1988; HANSEN; THOROE, 1990).

O LBP produz a estimulação de efeitos como a liberação de histamina, serotonina, e bradicinina, além de ativar a produção de ácido araquidônico, convertendo prostaglandinas em prostaciclina. Também aumenta a quantidade de ATP, acelera mitoses, melhora a reparação tecidual, estimula a reparação óssea, equilibra a produção de fibroblastos, com normalização de fibras colágenas e elásticas depositadas no tecido de reparação, e aumenta a circulação sanguínea periférica, melhorando a ação anti-inflamatória e a cicatrização do tecido (TAKEDA, 1988; SAITO; SHIMIZU, 1997; KAWASAKI; SHIMIZU, 2000; ANGELETTI et al., 2010).

Dado a importância da comprovação científica do controle ou não da dor pelo LBP, o presente estudo propôs-se a quantificar a presença da proteína $c$-fos nos neurônios de ratos submetidos à ERM associada ao LBP, para verificar a ação da laserterapia na expressão da proteína c-fos. Analisando a expressão da imunorreatividade da proteína c-fos, verificou-se que no grupo que foi irradiado com laser imediatamente após a expansão rápida da maxila (ERM+LBP) houve uma diminuição significativa em relação ao grupo que teve apenas a ERM no subnúcleo interpolaris no período de 6 h e na porção caudal do subnúcleo caudalis no período de $24 \mathrm{~h}$. Provavelmente se houvesse aplicação diária durante os 3 primeiros dias o 
comportamento da expressão da proteína c-fos teria sido distinto nos períodos posteriores.

O efeito do LBP na percepção da dor por pacientes em tratamento com aparelho ortodôntico fixo foi investigado clinicamente. Ao contrário de estudos prévios, o alívio da dor pela irradiação com o LBP foi avaliada imediatamente após a instalação dos aparelhos fixos e muitos pacientes foram estudados prospectivamente (NGAN; KESS; WILSON, 1989; HARAZAKI et al., 1998; TURHANI et al., 2006). Abreu et al. (2010) em estudo clínico concluiram que o LBP foi efetivo na redução da dor, além de acelerar na formação de osso em paciente submetido à ERM e várias aplicações de LBP. Estudos sobre o alívio da dor pelo LBP não se limitam ao tratamento ortodôntico fixo. Outros estudos têm mostrado alívio da dor pelo LBP após cirurgias endodônticas (KREISLER et al., 2004) e em pacientes com dor na articulação temporomandibular, neuralgia do trigêmeo, mialgia, e hipersensibilidade gengival (PINHEIRO et al., 1997; KULEKCIOGLU et al., 2003; TURHANI et al., 2006). Um estudo verificou a ação do laser sobre a intensidade da dor e capacidade funcional em pacientes com dor lombar aguda e crônica causada pela hérnia de disco lombar e não obteve diferenças entre tratamentos laser ou nãolaser (AY, DOGAN, EVCIK, 2010). Porém acreditamos que relatos sobre o efeito do LBP em relação à dor, devem ser interpretados com a devida atenção, pois três fatores podem influenciar nos resultados da análise: (1) a subjetividade da percepção da dor e limiar individual de cada paciente, (2) a variabilidade dos vários sistemas de laser atualmente comercializados, que diferem em especificações técnicas e modos de aplicação, e (3) metodologia utilizada. Entre estes sistemas estão os lasers, como o que foi utilizado na presente pesquisa (laser de GaAlAs, $830 \eta \mathrm{m})$, que é o mais utilizado para esta indicação. Porém os efeitos biológicos do LBP na nocicepção e sua atenuação ainda não estão totalmente compreendidos (TURHANI et al., 2006). Com os resultados apresentados na presente pesquisa, sugere-se que mais aplicações sejam realizadas principalmente nos períodos iniciais, a fim de controlar o processo inflamatório presente na região. Embora crucial para o sucesso do tratamento, a inflamação é a grande responsável pelas sensações desagradáveis, como o desconforto e a dor (NGAN; KESS; WILSON, 1989; JONES, M.; CHAN, C., 1992; KRISHNAN, 2007). Relatos clínicos descrevem que estas sensações surgem de maneira intensa um dia após o início da aplicação 
do estímulo, desaparecendo gradualmente e reaparecendo mais tarde (ERDINC; DINCER, 2004; KRISHNAN, 2007).

No presente estudo, observou-se no período de 6 horas uma redução significativa na expressão de c-fos no subnúcleo interpolaris do grupo ERM associada ao LBP em relação ao grupo ERM, embora os demais subnúcleos apresentassem uma tendência de diminuição da expressão de c-fos no grupo irradiado com LBP. Para verificar esta tendência, um levantamento quantitativo da intensidade da dor pré-tratamento seria necessário. Outra abordagem poderia ser avaliar a redução da dor após o tratamento com LBP em um curto intervalo de tempo, antes das 6 horas utilizado nesta pesquisa, bem como utilizar múltiplas aplicações do LBP.

Como mostrado, ambos os grupos (ERM e ERM+LBP) apresentaram um aumento estatisticamente significante na quantidade da proteína Fos, expressa pela imunorreatividade das células neurais. Por outro lado, este estudo mostrou evidências de que o LBP diminui a expressão da proteína Fos em algumas áreas. Aconselham-se novos experimentos com tempo de observação menor e com mais doses de aplicação do LBP.

É interessante notar que os primeiros relatos com a utilização do LBP para o controle da dor não foram reproduzidas por outros autores, e que quase todos os estudos placebo-controlado até agora tem falhado para identificar diferença entre o laser e placebo. O uso generalizado do LBP no tratamento de pacientes com dor é, primeiramente baseado em experiências empíricas e relatos de casos isolados. Apesar da escassez de documentação científica do efeito dos diferentes tipos de lasers em odontologia, parece haver um grande interesse pelo LBP entre os clínicos gerais e uma demanda para o tratamento a laser pelos pacientes (HANSEN; THOROE, 1990). Portanto o efeito de diferentes comprimentos de onda, frequência, modos de irradiação do laser devem ser levados em consideração na relação de diferentes condições patológicas bem definidas. Além disso, os efeitos a longo prazo precisam ser avaliados. 


\section{Conclusãa}




\section{CONCLUSÃo}

Este estudo experimental mostrou que a ERM aumentou a expressão da proteína Fos, principalmente logo após a aplicação da força ortopédica. Ao mesmo tempo mostrou que o LBP diminuiu a expressão da proteína Fos no núcleo espinhal do trigêmio, o que pode ser relacionado à redução da sensibilidade nociceptiva, tornando-se uma alternativa para o controle da dor durante as ativações frequentes do aparelho ortodôntico. Porém outras metodologias clínicas e experimentais devem ser utilizadas no intuito de confirmar estes resultados. 


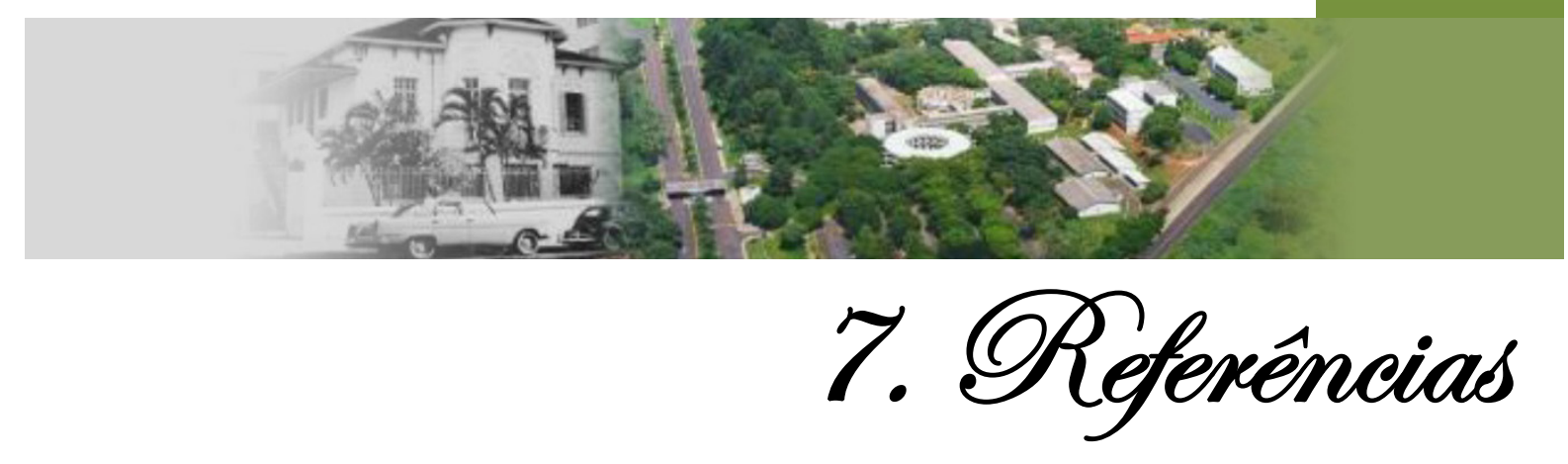




\section{REFERÊNCIAS ${ }^{1}$}

ABREU, M. E. et al. Infrared laser therapy after surgically assisted rapid palatal expansion to diminish pain and accelerate bone healing. World J Orthod, v.11, n.3, Fall, p.273-7. 2010.

AlHARA, Y. et al. Effects of morphine on the distribution of Fos protein in the trigeminal subnucleus caudalis neurons during experimental tooth movement of the rat molar. Brain Res, v.819, n.1-2, Feb 20, p.48-57. 1999.

ANGELETTI, P. et al. Effect of low-level laser therapy (GaAIAs) on bone regeneration in midpalatal anterior suture after surgically assisted rapid maxillary expansion. Oral Surg Oral Med Oral Pathol Oral Radiol Endod, v.109, n.3, Mar, p.e38-46. 2010.

ASHAM, A. A. Readers' forum: orthodontic pain. Am J Orthod Dentofacial Orthop, v.125, n.3, Mar, p.18A. 2004.

AY, S.; DOGAN, S. K.; EVCIK, D. Is low-level laser therapy effective in acute or chronic low back pain? Clin Rheumatol, v.29, n.8, Aug, p.905-10. 2010.

BASFORD, J. R. Low-energy laser treatment of pain and wounds: hype, hope, or hokum? Mayo Clin Proc, v.61, n.8, Aug, p.671-5. 1986.

BASFORD, J. R. et al. Low-energy helium neon laser treatment of thumb osteoarthritis. Arch Phys Med Rehabil, v.68, n.11, Nov, p.794-7. 1987.

BASFORD, J. R. Low-energy laser therapy: controversies and new research findings. Lasers Surg Med, v.9, n.1, p.1-5. 1989.

BERGIUS, M.; KILIARIDIS, S.; BERGGREN, U. Pain in orthodontics. A review and discussion of the literature. J Orofac Orthop, v.61, n.2, p.125-37. 2000.

BERTOLINI, G. R. et al. Low-level laser therapy, at $830 \mathrm{~nm}$, for pain reduction in experimental model of rats with sciatica. Arq Neuropsiquiatr, v.69, n.2B, p.356-9. 2011.

BESTER, H. et al. Further evidence for the involvement of the spinoparabrachial pathway in nociceptive processes: a c-Fos study in the rat. J Comp Neurol, v.383, n.4, Jul 14, p.439-58. 1997.

BONDEMARK, L.; FREDRIKSSON, K.; ILROS, S. Separation effect and perception of pain and discomfort from two types of orthodontic separators. World J Orthod, v.5, n.2, Summer, p.172-6. 2004.

\footnotetext{
${ }^{1}$ De acordo com a Associação Brasileira de Normas Técnicas. NBR 6023.
} 
BROWN, D. F.; MOERENHOUT R. G. The pain experience and psychological adjustment to orthodontic treatment of preadolescents, adolescents, and adults. Am J Orthod Dentofacial Orthop, v.100, n.4, Oct, p.349-56. 1991.

BYERS, M. R.; DONG W. K. Comparison of trigeminal receptor location and structure in the periodontal ligament of different types of teeth from the rat, cat, and monkey. J Comp Neurol, v.279, n.1, Jan 1, p.117-27. 1989.

COIMBRA, F.; COIMBRA A. Dental noxious input reaches the subnucleus caudalis of the trigeminal complex in the rat, as shown by $c$-fos expression upon thermal or mechanical stimulation. Neurosci Lett, v.173, n.1-2, May 23, p.201-4. 1994.

CRAIG, A. D. Spinal and trigeminal lamina I input to the locus coeruleus anterogradely labeled with Phaseolus vulgaris leucoagglutinin (PHA-L) in the cat and the monkey. Brain Res, v.584, n.1-2, Jul 3, p.325-8. 1992.

CURRAN, T.; MORGAN J. I.. Memories of fos. Bioessays, v.7, n.6, Dec, p.255-8. 1987.

DING, Y. Q. et al. Spinoparabrachial tract neurons showing substance $\mathbf{P}$ receptor-like immunoreactivity in the lumbar spinal cord of the rat. Brain Res, v.674, n.2, Mar 20, p.336-40. 1995.

DRAGUNOW, M.; FAULL. R. The use of c-fos as a metabolic marker in neuronal pathway tracing. J Neurosci Methods, v.29, n.3, Sep, p.261-5. 1989.

ERDINC, A. M.; DINCER, B. Perception of pain during orthodontic treatment with fixed appliances. Eur J Orthod, v.26, n.1, Feb, p.79-85. 2004.

FEIL, K.; HERBERT, H. Topographic organization of spinal and trigeminal somatosensory pathways to the rat parabrachial and Kolliker-Fuse nuclei. $J$ Comp Neurol, v.353, n.4, Mar 20, p.506-28. 1995.

FERREIRA, S. H.; NAKAMURA, M.; DE ABREU CASTRO, M. S. The hyperalgesic effects of prostacyclin and prostaglandin E2. Prostaglandins, v.16, n.1, Jul, p.317. 1978.

FIRESTONE, A. R.; SCHEURER, P. A.; BURGIN, W. B. Patients' anticipation of pain and pain-related side effects, and their perception of pain as a result of orthodontic treatment with fixed appliances. Eur J Orthod, v.21, n.4, Aug, p.38796. 1999.

FUJIYOSHI, Y. et al. The difference in temporal distribution of c-Fos immunoreactive neurons between the medullary dorsal horn and the trigeminal subnucleus oralis in the rat following experimental tooth movement. Neurosci Lett, v.283, n.3, Apr 14, p.205-8. 2000.

FURSTMAN, L.; BERNICK S. Clinical considerations of the periodontium. Am J Orthod, v.61, n.2, Feb, p.138-55. 1972. 
GAO, Y.; DUAN, Y. Z. Increased COX2 in the trigeminal nucleus caudalis is involved in orofacial pain induced by experimental tooth movement. Anat Rec (Hoboken), v.293, n.3, Mar, p.485-91. 2010.

GOLDMAN, J. A. et al. Laser therapy of rheumatoid arthritis. Lasers Surg Med, v.1, n.1, p.93-101. 1980.

GRIEVE, W. G. et al. Prostaglandin E (PGE) and interleukin-1 beta (IL-1 beta) levels in gingival crevicular fluid during human orthodontic tooth movement. Am J Orthod Dentofacial Orthop, v.105, n.4, Apr, p.369-74. 1994.

HANDELMAN, C. S. Nonsurgical rapid maxillary alveolar expansion in adults: a clinical evaluation. Angle Orthod, v.67, n.4, p.291-305; discussion 306-8. 1997.

HANSEN, H. J.; THOROE, U. Low power laser biostimulation of chronic orofacial pain. A double-blind placebo controlled cross-over study in $\mathbf{4 0}$ patients. Pain, v.43, n.2, Nov, p.169-79. 1990.

HARAZAKI, M.; ISSHIKI, Y. Soft laser irradiation effects on pain reduction in orthodontic treatment. Bull Tokyo Dent Coll, v.38, n.4, Nov, p.291-5. 1997.

HARAZAKI, M. et al. Soft laser irradiation induced pain reduction in orthodontic treatment. Bull Tokyo Dent Coll, v.39, n.2, May, p.95-101. 1998.

HARRIS, J. A. Descending antinociceptive mechanisms in the brainstem: their role in the animal's defensive system. J Physiol Paris, v.90, n.1, p.15-25. 1996.

HAYNES, S. Discontinuation of orthodontic treatment relative to patient age. J Dent, v.2, n.4, Jul, p.138-42. 1974.

HIROSHIMA, K. et al. Temporal and spatial distribution of Fos protein in the parabrachial nucleus neurons during experimental tooth movement of the rat molar. Brain Res, v.908, n.2, Jul 27, p.161-73. 2001.

HONMURA, A. et al. Therapeutic effect of Ga-Al-As diode laser irradiation on experimentally induced inflammation in rats. Lasers Surg Med, v.12, n.4, p.441-9. 1992.

HU, J. W.; SESSLE, B. J. Comparison of responses of cutaneous nociceptive and nonnociceptive brain stem neurons in trigeminal subnucleus caudalis (medullary dorsal horn) and subnucleus oralis to natural and electrical stimulation of tooth pulp. J Neurophysiol, v.52, n.1, Jul, p.39-53. 1984.

HUNT, S. P.; PINI, A.; EVAN, G. Induction of c-fos-like protein in spinal cord neurons following sensory stimulation. Nature, v.328, n.6131, Aug 13-19, p.6324. 1987.

HYLDEN, J. L.; ANTON, F.; NAHIN, R. L. Spinal lamina I projection neurons in the rat: collateral innervation of parabrachial area and thalamus. Neuroscience, v.28, n.1, p.27-37. 1989. 
ITO, A. et al. Effects of Nd: YAG low power laser irradiation on the ulnar nerve. Aichi Gakuin Dent Sci, v.2, p.1-8. 1989.

JASMIN, L. et al. Transneuronal labeling of a nociceptive pathway, the spino(trigemino-) parabrachio-amygdaloid, in the rat. J Neurosci, v.17, n.10, May 15, p.3751-65. 1997.

JENSEN, H.; HARREBY, M.; KJER, J. Infrared laser--effect in painful arthrosis of the knee? Ugeskr Laeger, v.149, n.46, Nov 9, p.3104-6. 1987.

JONES, M. L. An investigation into the initial discomfort caused by placement of an archwire. Eur J Orthod, v.6, n.1, Feb, p.48-54. 1984.

JONES, M.; CHAN, C. The pain and discomfort experienced during orthodontic treatment: a randomized controlled clinical trial of two initial aligning arch wires. Am J Orthod Dentofacial Orthop, v.102, n.4, Oct, p.373-81. 1992.

JONES, M. L.; CHAN, C. Pain in the early stages of orthodontic treatment. J Clin Orthod, v.26, n.5, May, p.311-3. 1992.

JOVILIANO, P. Expressão temporal de c-fos em estruturas neurais relacionadas à (anti-) nocicepção após movimentação dentária experimental. (Dissertação de Mestrado). Departamento de Fisiologia, Faculdade de Medicina de Ribeirão Preto, Universidade de São Paulo, Ribeirão Preto, SP., 2006.

JOVILIANO, P. et al. Rapid maxillary expansion causes neuronal activation in brain structures of rats. Brain Res Bull, v.76, n.4, Jul 1, p.396-401. 2008.

KAMOGASHIRA, K. et al. The effects of upper incisor separation on the submandibular and sublingual glands of rats. J Dent Res, v.67, n.3, Mar, p.60210. 1988.

KARU, T. Photobiology of low-power laser effects. Health Phys, v.56, n.5, May, p.691-704. 1989.

KATO, J. et al. Induction of Fos protein in the rat trigeminal nucleus complex during an experimental tooth movement. Arch Oral Biol, v.39, n.8, Aug, p.723-6. 1994.

KATO, J.; WAKISAKA, S.; KURISU, K. Immunohistochemical changes in the distribution of nerve fibers in the periodontal ligament during an experimental tooth movement of the rat molar. Acta Anat (Basel), v.157, n.1, p.53-62. 1996.

KAWASAKI, K.; SHIMIZU, N. Effects of low-energy laser irradiation on bone remodeling during experimental tooth movement in rats. Lasers Surg Med, v.26, n.3, p.282-91. 2000.

KEIM, R. G. Managing orthodontic pain. J Clin Orthod, v.38, n.12, Dec, p.641-2. 2004. 
KHULLAR, S. M. et al. Preliminary study of low-level laser for treatment of longstanding sensory aberrations in the inferior alveolar nerve. J Oral Maxillofac Surg, v.54, n.1, Jan, p.2-7; discussion 7-8. 1996.

KLATT, D. S. et al. The dorsal raphe nucleus: a re-evaluation of its proposed role in opiate analgesia systems. Brain Res, v.447, n.2, May 3, p.246-52. 1988.

KLUEMPER, G. T. et al. Efficacy of a wax containing benzocaine in the relief of oral mucosal pain caused by orthodontic appliances. Am J Orthod Dentofacial Orthop, v.122, n.4, Oct, p.359-65. 2002.

KNAPPE, V.; FRANK, F.; ROHDE, E. Principles of lasers and biophotonic effects. Photomed Laser Surg, v.22, n.5, Oct, p.411-7. 2004.

KOBAYASHI, $\mathrm{H}$. et al. Alterations in ultrastructural localization of growthassociated protein-43 (GAP-43) in periodontal Ruffini endings of rat molars during experimental tooth movement. J Dent Res, v.77, n.3, Mar, p.503-17. 1998.

KREISLER, M. B. et al. Efficacy of low level laser therapy in reducing postoperative pain after endodontic surgery- a randomized double blind clinical study. Int J Oral Maxillofac Surg, v.33, n.1, Jan, p.38-41. 2004.

KRISHNAN, V. Orthodontic pain: from causes to management-a review. Eur J Orthod, v.29, n.2, Apr, p.170-9. 2007.

KULEKCIOGLU, S. et al. Effectiveness of low-level laser therapy in temporomandibular disorder. Scand J Rheumatol, v.32, n.2, p.114-8. 2003.

KVINNSLAND, I.; KVINNSLAND, S. Changes in CGRP-immunoreactive nerve fibres during experimental tooth movement in rats. Eur J Orthod, v.12, n.3, Aug, p.320-9. 1990.

LAZAROV, N. E. The mesencephalic trigeminal nucleus in the cat. Adv Anat Embryol Cell Biol, v.153, p.iii-xiv, 1-103. 2000.

LI, Y. Q. et al. Identification of periaqueductal gray and dorsal raphe nucleus neurons projecting to both the trigeminal sensory complex and forebrain structures: a fluorescent retrograde double-labeling study in the rat. Brain Res, v.623, n.2, Oct 1, p.267-77. 1993.

LIM, H. M.; LEW, K. K.; TAY, D. K. A clinical investigation of the efficacy of low level laser therapy in reducing orthodontic postadjustment pain. Am $\mathrm{J}$ Orthod Dentofacial Orthop, v.108, n.6, Dec, p.614-22. 1995.

LUNDEBERG, T.; HAKER, E.; THOMAS, M. Effect of laser versus placebo in tennis elbow. Scand J Rehabil Med, v.19, n.3, p.135-8. 1987.

LYONS, R. F. et al. Biostimulation of wound healing in vivo by a helium-neon laser. Ann Plast Surg, v.18, n.1, Jan, p.47-50. 1987.

MAGDALENA, C. M. et al. C-fos expression in rat brain nuclei following incisor tooth movement. J Dent Res, v.83, n.1, Jan, p.50-4. 2004. 
MAO, J. J. Mechanobiology of craniofacial sutures. J Dent Res, v.81, n.12, Dec, p.810-6. 2002.

MAO, J. J.; WANG, X.; KOPHER, R. A. Biomechanics of craniofacial sutures: orthopedic implications. Angle Orthod, v.73, n.2, Apr, p.128-35. 2003.

MARCOS, R. L. et al. Infrared $(810 \mathrm{~nm})$ low-level laser therapy in rat achilles tendinitis: a consistent alternative to drugs. Photochem Photobiol, v.87, n.6, NovDec, p.1447-52. 2011.

MELZACK, R. The McGill Pain Questionnaire: major properties and scoring methods. Pain, v.1, n.3, Sep, p.277-99. 1975.

MESTER, E. et al. Effect of laser rays on wound healing. Am J Surg, v.122, n.4, Oct, p.532-5. 1971.

MESTER, E. et al. Stimulation of wound healing by means of laser rays. Part III-Investigation of the effect on immune competent cells. Acta Chir Acad Sci Hung, v.19, n.2, p.163-70. 1978.

MESTER, E.; MESTER, A. F.; MESTER, A. The biomedical effects of laser application. Lasers Surg Med, v.5, n.1, p.31-9. 1985.

MEZAWA, S. et al. The possible analgesic effect of soft-laser irradiation on heat nociceptors in the cat tongue. Arch Oral Biol, v.33, n.9, p.693-4. 1988.

MILLAN, M. J. Descending control of pain. Prog Neurobiol, v.66, n.6, Apr, p.355474. 2002.

MORGAN, J. I.; CURRAN, T. Role of ion flux in the control of c-fos expression. Nature, v.322, n.6079, Aug 7-13, p.552-5. 1986.

MORGAN, M. M. et al. Antinociception mediated by the periaqueductal gray is attenuated by orphanin FQ. Neuroreport, v.8, n.16, Nov 10, p.3431-4. 1997.

NANAMI, T. et al. Clinical applications and basic studies of laser in dentistry and oral surgery. Keio J Med, v.42, n.4, Dec, p.199-201. 1993.

NEEDLEMAN, H. L. et al. Reports of pain by children undergoing rapid palatal expansion. Pediatr Dent, v.22, n.3, May-Jun, p.221-6. 2000.

NEIBURGER, E. J. Accelerated healing of gingival incisions by the helium-neon diode laser: a preliminary study. Gen Dent, v.45, n.2, Mar-Apr, p.166-70. 1997.

NGAN, P.; KESS, B.; WILSON, S. Perception of discomfort by patients undergoing orthodontic treatment. Am J Orthod Dentofacial Orthop, v.96, n.1, Jul, p.47-53. 1989.

O'CONNOR, P. J. Patients' perceptions before, during, and after orthodontic treatment. J Clin Orthod, v.34, n.10, Oct, p.591-2. 2000. 
OLIVER, R. G.; KNAPMAN, Y. M. Attitudes to orthodontic treatment. Br J Orthod, v.12, n.4, Oct, p.179-88. 1985.

PANNETON, W. M.; JOHNSON, S. N.; CHRISTENSEN, N. D.Trigeminal projections to the peribrachial region in the muskrat. Neuroscience, v.58, n.3, Feb, p.605-25. 1994.

PAXINOS, G.; WATSON, C. The rat brain in stereotaxic coordinates. Amsterdam ; Boston: Elsevier Academic Press. 2005.

PINHEIRO, A. L. et al. Low-level laser therapy in the management of disorders of the maxillofacial region. J Clin Laser Med Surg, v.15, n.4, p.181-3. 1997.

POLAT, O.; KARAMAN, A. I. Pain control during fixed orthodontic appliance therapy. Angle Orthod, v.75, n.2, Mar, p.214-9. 2005.

ROCHA, M. J.; HERBERT, H. Effects of anesthetics on Fos protein expression in autonomic brain nuclei related to cardiovascular regulation. Neuropharmacology, v.36, n.11-12, Nov-Dec, p.1779-81. 1997.

ROTH, P. M.; THRASH, W. J. Effect of transcutaneous electrical nerve stimulation for controlling pain associated with orthodontic tooth movement. Am J Orthod Dentofacial Orthop, v.90, n.2, Aug, p.132-8. 1986.

SAGAR, S. M.; SHARP, F. R.; CURRAN, T. Expression of c-fos protein in brain: metabolic mapping at the cellular level. Science, v.240, n.4857, Jun 3, p.1328-31. 1988.

SAITO, I. et al. Responses of calcitonin gene-related peptide-immunopositive nerve fibres in the periodontal ligament of rat molars to experimental tooth movement. Arch Oral Biol, v.36, n.9, p.689-92. 1991.

SAITO, S.; SHIMIZU, N. Stimulatory effects of low-power laser irradiation on bone regeneration in midpalatal suture during expansion in the rat. Am $\mathrm{J}$ Orthod Dentofacial Orthop, v.111, n.5, May, p.525-32. 1997.

SANDY, J. R.; FARNDALE, R. W.; MEIKLE, M. C. Recent advances in understanding mechanically induced bone remodeling and their relevance to orthodontic theory and practice. Am J Orthod Dentofacial Orthop, v.103, n.3, Mar, p.212-22. 1993.

SAWADA, M.; SHIMIZU, N. Stimulation of bone formation in the expanding midpalatal suture by transforming growth factor-beta 1 in the rat. Eur $\mathrm{J}$ Orthod, v.18, n.2, Apr, p.169-79. 1996.

SCHEURER, P. A.; FIRESTONE, A. R.; BURGIN, W. B. Perception of pain as a result of orthodontic treatment with fixed appliances. Eur J Orthod, v.18, n.4, Aug, p.349-57. 1996.

SCHUSTER, G.; BOREL-SCHERF, I.; SCHOPF, P. M. Frequency of and complications in the use of RPE appliances - results of a survey in the Federal State of Hesse, Germany. J Orofac Orthop, v.66, n.2, Mar, p.148-61. 2005. 
SESSLE, B. J. Acute and chronic craniofacial pain: brainstem mechanisms of nociceptive transmission and neuroplasticity, and their clinical correlates. Crit Rev Oral Biol Med, v.11, n.1, p.57-91. 2000.

SGOLASTRA, F. et al. Effectiveness of laser in dentinal hypersensitivity treatment: a systematic review. J Endod, v.37, n.3, Mar, p.297-303. 2011.

SHIMIZU, K. et al. Phosphorylation of Extracellular Signal-Regulated Kinase in medullary and upper cervical cord neurons following noxious tooth pulp stimulation. Brain Res, v.1072, n.1, Feb 9, p.99-109. 2006.

SIMPSON, K. L. et al. Lateralization and functional organization of the locus coeruleus projection to the trigeminal somatosensory pathway in rat. J Comp Neurol, v.385, n.1, Aug 18, p.135-47. 1997.

SLUGG, R. M.; LIGHT, A. R. Spinal cord and trigeminal projections to the pontine parabrachial region in the rat as demonstrated with Phaseolus vulgaris leucoagglutinin. J Comp Neurol, v.339, n.1, Jan 1, p.49-61. 1994.

SNYDER-MACKLER, L. et al. Effect of helium-neon laser on musculoskeletal trigger points. Phys Ther, v.66, n.7, Jul, p.1087-90. 1986.

SOLTIS, J. E.; NAKFOOR, P. R.; BOWMAN, D. C. Changes in ability of patients to differentiate intensity of forces applied to maxillary central incisors during orthodontic treatment. J Dent Res, v.50, n.3, May-Jun, p.590-6. 1971.

STABILE, A. C. Efeito do acetaminofeno e do celecoxib na distalização de incisivos e na ativação de regiões cerebrais relacionadas à nocicepcão durante a movimentação ortodôntica em ratos (Dissertação de Mestrado). Departamento de Materiais Dentários e Prótese da Faculdade de Odontologia de Ribeirão Preto da Universidade de São PauloRibeirão Preto e de São Paulo, 2008.

STABILE, A. C. et al. Effects of short-term acetaminophen and celecoxib treatment on orthodontic tooth movement and neuronal activation in rat. Brain Res Bull, v.79, n.6, Aug 14, p.396-401. 2009.

STOREY, E. The nature of tooth movement. Am J Orthod, v.63, n.3, Mar, p.292314. 1973.

SUGIMOTO, T. et al. c-fos induction in the subnucleus caudalis following noxious mechanical stimulation of the oral mucous membrane. Exp Neurol, v.129, n.2, Oct, p.251-6. 1994.

TAKEDA, Y. Irradiation effect of low-energy laser on alveolar bone after tooth extraction. Experimental study in rats. Int J Oral Maxillofac Surg, v.17, n.6, Dec, p.388-91. 1988.

TAKEMURA, M. et al. Mechanisms of orofacial pain control in the central nervous system. Arch Histol Cytol, v.69, n.2, Jun, p.79-100. 2006. 
TEN CATE, A. R.; FREEMAN, E.; DICKINSON, J. B. Sutural development: structure and its response to rapid expansion. Am J Orthod, v.71, n.6, Jun, p.622-36. 1977.

TITZE-DE-ALMEIDA, R. et al. Midazolam and the N-methyl-D-aspartate (NMDA) receptor antagonist 2-amino-7-phosphonoheptanoic acid (AP-7) attenuate stress-induced expression of c-fos mRNA in the dentate gyrus. Cell Mol Neurobiol, v.14, n.4, Aug, p.373-80. 1994.

TRULSSON, M.; JOHANSSON, R. S. Encoding of tooth loads by human periodontal afferents and their role in jaw motor control. Prog Neurobiol, v.49, n.3, Jun, p.267-84. 1996.

TSUCHIYA, K. et al. Diode laser irradiation selectively diminishes slow component of axonal volleys to dorsal roots from the saphenous nerve in the rat. Neurosci Lett, v.161, n.1, Oct 14, p.65-8. 1993.

TSUCHIYA, K. et al. Laser irradiation abates neuronal responses to nociceptive stimulation of rat-paw skin. Brain Res Bull, v.34, n.4, p.369-74. 1994.

TURHANI, D. et al. Pain relief by single low-level laser irradiation in orthodontic patients undergoing fixed appliance therapy. Am J Orthod Dentofacial Orthop, v.130, n.3, Sep, p.371-7. 2006.

WAKISAKA, S. et al. Increase in c-fos-like immunoreactivity in the trigeminal nucleus complex after dental treatment. Proc Finn Dent Soc, v.88 Suppl 1, p.5515. 1992.

WALDO, C. M.; ROTHBLATT, J. M. Histologic response to tooth movement in the laboratory rat; procedure and preliminary observations. J Dent Res, v.33, n.4, Aug, p.481-6. 1954.

WALKER, J. Relief from chronic pain by low power laser irradiation. Neurosci Lett, v.43, n.2-3, Dec 30, p.339-44. 1983.

WANG, L. G.; LI, H. M.; LI, J. S. Formalin induced FOS-like immunoreactive neurons in the trigeminal spinal caudal subnucleus project to contralateral parabrachial nucleus in the rat. Brain Res, v.649, n.1-2, Jun 27, p.62-70. 1994.

WANG, Q. P.; NAKAI, Y. The dorsal raphe: an important nucleus in pain modulation. Brain Res Bull, v.34, n.6, p.575-85. 1994.

WAYLONIS, G. W. et al. Chronic myofascial pain: management by low-output helium-neon laser therapy. Arch Phys Med Rehabil, v.69, n.12, Dec, p.1017-20. 1988.

WEWERS, M. E.; LOWE, N. K. A critical review of visual analogue scales in the measurement of clinical phenomena. Res Nurs Health, v.13, n.4, Aug, p.227-36. 1990. 
YAMASHIRO, T. et al. c-fos expression in the trigeminal sensory complex and pontine parabrachial areas following experimental tooth movement. Neuroreport, v.8, n.9-10, Jul 7, p.2351-3. 1997.

YAMASHIRO, T. et al. Expression of Fos in the rat forebrain following experimental tooth movement. J Dent Res, v.77, n.11, Nov, p.1920-5. 1998.

ZARKOVIC, N. et al. Effect of semiconductor GaAs laser irradiation on pain perception in mice. Lasers Surg Med, v.9, n.1, p.63-6. 1989. 


\section{Anexa}




\title{
8. ANEXO
}

\section{ANEXO A- Folha de Aprovação do Projeto de Pesquisa na Comissão de Ética no Uso de Animais}

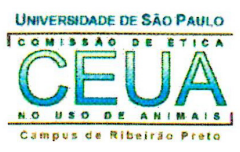

\author{
UNIVERSIDADE DE SÃO PAULO \\ Campus de Ribeirão Preto \\ Comissão de Ética no Uso de Animais
}

\section{E R T I F I C A D O}

Certificamos que o trabalho (Protocolo $n^{\circ}$ 09.1.1449.53.2), intitulado "Efeito do Laser de Baixa Potência Após a Expansão Rápida da Maxila na Ativação de Regiões Cerebrais Relacionadas à Nocicepção", de autoria de Elaine Machado Pingueiro e de Maria Bernadete Sasso Stuani por estar de acordo com os Princípios Éticos na Experimentação Animal adotado pela Comissão de Ética no Uso de Animais (CEUA) do Campus de Ribeirão Preto - USP foi aprovado em reunião da CEUA de 03/03/2010

This is to certify that the work (Protocol number 09.1.1449.53.2), entitled: "Efeito do Laser de Baixa Potência Após a Expansão Rápida da Maxila na Ativação de Regiões Cerebrais Relacionadas à Nocicepção", by Elaine Machado Pingueiro and Maria Bernadete Sasso Stuani, is in accordance with the Ethic Principles in Animal Experimentation adopted by Ethic Commission for the Use of Animals (CEUA) of the Campus of Ribeirão Preto - USP, and was approved in the meeting, March, 03, 2010.

Ribeirão Preto, 26 de abril de 2010

Quista Leite Rainso

Presidente da CEUA

Profa.Dra. Christie Ramos Andrade Leite Panissi

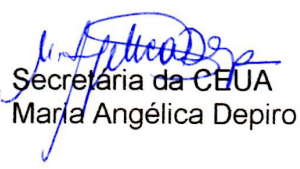

Av. Bandeirantes, 3900 - CEP 14040-900 - Ribeirão Preto - São Paulo Fone: (16) 36024469 - Fax: (16) 36337964 